\title{
Learners' Conceptual Knowledge Development and Attitudinal Change towards Calculus Using Jigsaw Co-operative Learning Strategy Integrated with GeoGebra
}

\author{
Sirak Tsegaye Yimer ${ }^{1 *}$, Nosisi Nellie Feza ${ }^{2}$ \\ ${ }^{1}$ Ambo University, College of Natural and Computational Sciences, Mathematics Department, Ambo, Oromia, ETHIOPIA \\ ${ }^{2}$ Central University of Technology, Faculty of Humanities, Free State (CUT) Private Bag X20539, Bloemfontein, 9300, SOUTH \\ AFRICA \\ *CORRESPONDENCE: $\square$ sirakbeliyu@gmail.com
}

\begin{abstract}
This study examined the influence of the jigsaw co-operative learning strategy integrated with GeoGebra (JCLGS), on Ethiopian undergraduate statistics and chemistry learners' conceptual knowledge development and attitudinal change towards calculus. The post-positivism quantitative methods approach employed in a non-equivalent pre-and post-test comparison group quasi-experimental design. The samples had drawn using two-stage random sampling techniques. The sample size was 150 in both the experimental and comparison groups. Data were collected by using the calculus classroom achievement test and the five points Likert-scale attitude questionnaire. Data were analyzed using descriptive analysis, an independent-samples t-test and Two-Way ANOVA for repeated measures using SPSS 23.0. The results showed a statistically significant difference between the two groups of pre-post test scores on the Two-Way ANOVA, $F(1,148)=106.913 ; \eta^{2}=.419 ; p<.01$. The finding also implies that the blended learning strategy grounded in Vygotsky's social constructivism cognitive development learning theory had big practical significance on learners' conceptual knowledge development. Learners viewed the JCLGS as enjoyable and interesting. It was also a socially interactive and collaborative environment that allows learners' to be reflective, share prior experience and knowledge and independent learners. It encourages them to have a positive attitude towards calculus and GeoGebra. Because of this finding, mathematics and science educators are advised to model a similar blended learning strategy in a classroom instructional setting. It will benefit their learners to adequately construct conceptual knowledge and positively change their attitude towards mathematics.
\end{abstract}

Keywords: attitudinal change, calculus, conceptual knowledge development, GeoGebra, jigsaw co-operative learning strategy

\section{INTRODUCTION}

Anyone who engaged in university teaching/learning is familiar with the fact that as mathematics and science learners enrolled for intermediate calculus in their degree program study. In Ethiopian public universities' harmonized modular curriculum, this course is offered for undergraduate first-year Mathematics, Physics, Chemistry and Statistics learners. It is a fundamental and very applicable course in science, engineering, technology and some social science disciplines (Othman, Tarmuji, \& Hilmi, 2017). The reason is that the various ideas involved in it can be used to concisely describe and model problems involving a change

Article History: Received 8 June $2019 \bullet$ Revised 15 August $2019 \bullet$ Accepted 11 September 2019

(C) 2020 by the authors; licensee Modestum Ltd., UK. Open Access terms of the Creative Commons Attribution 4.0 International License (http://creativecommons.org/licenses/by/4.0/) apply. The license permits unrestricted use, distribution, and reproduction in any medium, on the condition that users give exact credit to the original author(s) and the source, provide a link to the Creative Commons license, and indicate if they made any changes. 
in real-life circumstances. In support of this, Boz Yaman (2019) states that calculus learning can be regarded as a starting point where learners' understanding of real-life problems in areas like science and engineering emerge through mathematics. To qualify that degree, learners should adequately be equipped with the pertinent knowledge, skill, and attitude in the stipulated syllabus. The goal of any university is, therefore, to create a conducive learning environment for learners better learn and then to achieve the desired learning outcome.

However, most learners have been challenged and developed a negative attitude towards calculus learning through the traditional lecture method. They perceive as mathematicians do not have a normal way of life as another person. This led them to view as the learning of calculus/mathematics is not as normal as other courses. They generally dislike all mathematics courses offered in universities. Overall, they have developed a phobia towards any mathematics learning. In connection to this, Mazana, Suero Montero, and Olifage (2019) reported learners' attitudes towards mathematics and teaching methods that teachers employ affect their learning and performance. There has been an intention to introduce and further extend the use of the active learning strategy in learners' learning of all subjects in Ethiopian public universities. This is because of the shortcoming of the traditional lecture method in an instructional setting. The Higher Diploma Program (HDP) training given in every public university of Ethiopia for instructors' professional development is evidence of that. The intention is to equip instructors, how to appropriately use any active learning strategies in classroom instruction as well as to develop the skill of how to conduct action research. By this means, the teaching of every subject will become research-based instruction. This would help instructors to give an immediate solution for learners' calculus learning challenges and the overall problem in the process of classroom instructional. Boz Yaman (2019) in Turkey also shares this same idea that the traditional teaching and learning models need to be transformed into a new active teaching/learning models in classroom instruction.

Instructors are the main responsible bodies in the university community who must facilitate such a learning environment that helps learners to own conceptual knowledge and positively change their attitudes towards calculus. As most mathematics education research literature findings indicated, for instance in Peteros, Columna, Etcuban, Almerino, and Almerino (2019), learners' attitude affects their achievement scores of mathematics and vice-versa. That was the reason why this research project intends to study these constructs jointly. They represent the main components of the theoretical framework. To alleviate learners' performance and attitude in calculus, understanding all about the essence of conceptual and procedural knowledge is very fundamental. However, let alone learners, even instructors have a limited knowledge as content knowledge interconnects conceptual and procedural knowledge of mathematics (Chinnappan \& Forrester, 2014). Chinnappan and Forrester (2014) indicates that most teachers do not have full information and awareness on how to wisely use appropriate learning strategy that is a typical element of their pedagogical knowledge in students' mathematics learning. This same article describes that teachers' content and pedagogical knowledge impact each other. According to Ball, Thames, and Phelps (2008), content knowledge refers to the interrelation between conceptual and procedural knowledge of mathematics. Conceptual knowledge (CK) refers to mathematical knowledge of concepts rich in relationships, principles, and definitions, as well as understanding the relationships among mathematical objects (Chinnappan \& Forrester, 2014; Hiebert \& Lefevre, 1986; Star \& Stylianides, 2013). Procedural knowledge (PK) is defined as a mathematical knowledge of procedures involving an understanding of the rules or action sequences/algorithms, symbols and notations of mathematics used in problem-solving (Chinnappan \& Forrester, 2014; Hiebert \& Lefevre, 1986; Star \& Stylianides, 2013). Because of this fact and the knowledge gap in the literature, a need arisen to look for the active jigsaw cooperative learning strategy integrated with GeoGebra to be used for nurturing experimental group learners' in their calculus learning to fill the gap. In this ever-advancing digital era, utilizing the active learning strategy integrated with a computer software package used for calculus learning is very indispensable. Kandemir and Demirbağ-Keskin (2019) indicated that integrating technological tool used for teaching/learning mathematics into education has become a vital issue in science and mathematics education. This is because these days learners are exposed to various computer technologies in almost all their daily life. If instructors appropriately apply in classroom instruction, it most likely alleviates learners' conceptual knowledge (CK) learning challenge and their attitude problem towards calculus. Such a kind of learning strategy entertains learners' various learning styles and raises their motivation and interest. However, most instructors are refused to apply that, may be because of a long-ago influence of the use of traditional way of teaching or skill problem of manipulating mathematics software package or their attitude problem. According to Lavicza (2010), teachers' beliefs and conceptions towards integrating mathematics software packages generally, CAS in mathematics learning, were also the other factors linked with this learning challenge. Implementation of it requires them in taking great care and proficiency. Educators need to be engaged in 
careful planning, designing, implementation and evaluation of it. If they can pay special attention in good preparation of it in advance, learners' imagination and visualizing capacity of abstract concepts could be substantially enhanced. Learners could develop the habit of sharing their prior experiences, knowledge and practices in the underlying socially interactive learning environment. According to Ayub, Sembok, and Luan (2008), it also minimizes their cognitive load and even saves time for instructors that reduce the burden in their explanation. Arbini (2016) reported that the graphic calculator is one of the technological tools that enable learners' to improve their mathematics learning performance and achievement. In the findings of Parrot and Leong (2018), it verified as the graphing calculator impacts learners' problem-solving performance of linear equations and their attitude towards problem-solving methods. This can be become a reality through creating an appropriate awareness on every learner to be responsible and take his/her share the ultimately to own the learning. Instructors must create a conducive learning environment for learners that help them accomplish the desired calculus learning as properly as possible. Through this way that learners can minimize their misconceptions and misunderstanding of objects in calculus whereas increasing their conceptualization and abstraction potential and then ultimately get quality calculus learning in this digital era.

Co-operative learning strategy is of a typical active learning strategy that often entertains such a multifaceted purpose in learners' calculus knowledge, skill and positive attitude development. As Arbin, Ghani, and Hamzah (2014) pointed-out, co-operative learning strategy could make learners be motivated and have a positive attitude towards the available learning material. Sofroniou and Poutos (2016) reported that cooperative learning allows learners to think analytically and critically, enhance their teamwork sprit, independent learning, develop communication skills and acquire techniques of solving classroom or real-life problems. GeoGebra is a free source online available dynamic mathematics software package designed for teaching geometry, algebra and calculus. As Alkhateeb and Al-Duwairi (2019) indicated, GeoGebra can be used as a tool to facilitate understanding and ease visualization of abstract concepts of these lessons. This is through representing the same calculus notion in multiple ways such as numerically, symbolically, algebraically, geometrically, graphically and calculus means. However, most educators have very limited knowledge as to the use of such a learning strategy that integrates the active jigsaw co-operative learning strategy and GeoGebra. It could adequately enhance learners' conceptual knowledge development and stimulate them to have a positive attitude towards calculus. It was not appropriately utilized in such a way that a small degree by developed countries and worse by developing countries. According to Arbin et al. (2014); Engelbrecht, Bergsten, and Kågesten (2012); Kadijević (1999); Summit and Rickards (2013), almost all instructors have often imparted every bit of calculus lessons using traditional lecture method. This was carried out emphasizing at only addressing learners' procedural knowledge performance and achievement. Even their assessment techniques only focused on evaluating learners' knowledge of procedures. In contrast, they almost neglected learners' conceptual knowledge development. For that matter, learners' performance and achievement on procedural knowledge of calculus were not that satisfactory. This, in turn, has made learners not to act by the given situation while looking for a solution to given real-life problems. Furthermore, they seem to become inflexible who are providing poor evaluation and judgment and generally is uncreative about any mathematical problem issue under consideration. Generally, the traditional lecture method aggravated learners' calculus learning challenges that they are unable to develop conceptual and procedural knowledge hand-in-hand. According to Chinnappan and Forrester (2014); Kridler (2012), such an approach was called the balanced and connected or iterative that highly emphasized at developing this two knowledge through going back and forth. In other words, it refers to the development of content knowledge. As to the researcher experience and knowledge backup by literature, both instructors and learners have emphasized on procedural knowledge development of calculus. Despite that, especially learners' conceptual knowledge learning challenge of calculus has ever become duplicating. By this or other reasons, the number of learners enrolling in the mathematics department of one of the two universities where this research project was undertaken has ever decreased. For example, in the years 2015, 2016, and 2017, the numbers of learners enrolled in the mathematics department were respectively 22, 19 and 18. Maltas and Prescott (2014) have reflected similar idea as the number of learners taking higher-level mathematics subjects especially those involving calculus decreases and not taking mathematics increases in Australia. Maltas also reported that stakeholders such as politicians, parents, learners, universities and education departments have worried as to the ever-expanding of learners' learning challenge of mathematics at all levels. Maltas and Prescott (2014); Othman et al. (2017) also indicated that the challenge has become magnified when learners are advancing to higher education. Especially when entered into the university they exposed to the learning of calculus involving the limit concept that requires critical thinking and logical reasoning. All the time learners have been challenged learning of limit concept with traditional lecture method through black/whiteboard. You know that the notions continuity, 
derivative and integral entirely rely on it. The limit concept is a very abstract concept that involves mathematical objects that are fixed and in motion. The knowledge through which learners would gain is somewhat abstract that is only constructed in their brain. According to Piaget such knowledge is known as logico-mathematical or metaphysical knowledge (Getie, 2013). Due to this, learners' understanding and visualizing of these mathematical objects using traditional lecture method using black/whiteboard have challenged them. Moreover, Bezuidenhout (2001); Engelbrecht, Harding, and Potgieter (2005); Kadijević (1999) indicated that traditional lecture method in calculus learning was applied at only addressing procedural knowledge while neglecting conceptual knowledge. Similarly, Jaafar and Lin (2017); Kadijević (1999) further explained that these procedural/instrumental skills are initially cultivated through resolving procedural tasks involving fully quantified objects that learners often solve by using appropriate remembered rules without knowing why they work. Learners do not even realize why procedural skills are appropriate in a given situation and what the process means (Summit \& Rickards, 2013). They assume as it allows them to obtain temporary knowledge or short-lived on which good marks in tests/examinations could be easily obtained (Jaafar \& Lin, 2017). For that matter, this situation has been encouraged by instructors in their assessment procedures and pedagogy. Khashan (2014) also supported this same perspective that traditional method of teaching mathematics on rational numbers has largely focused on procedural knowledge almost ignoring the teaching of conceptual knowledge. Awang and Hamid (2015) also indicated as learners have shown a positive attitude towards procedural knowledge aspects of mathematics such as rules and formulas because these notions are most likely be viewed by them that easily grasped through rote learning.

However, Lim-Teo, Ahuja, and Lee (1999) stated some learners have had learning difficulty on conceptual knowledge like concepts, definitions, theorems and proofs. Besides that, Huang (2011) has indicated as the traditional way of teaching makes learners develop a negative and moderate positive attitude towards learning mathematics. Younga et al. (2011) also showed that learners specializing in Science, Technology, Engineering or Mathematics (STEM) have had difficulties in calculus learning. Ayub et al. (2008); Lee (2012); Zulnaidi and Zakaria (2012) pointed-out that, those researches conducted on learning supported with various mathematics software packages generally CAS even resulted in the inconsistent result as compared to traditional lecture method of calculus learning. Therefore, this study investigated the active jigsaw co-operative learning strategy, integrated with Geogebra has significantly influenced learners' conceptual knowledge development and their attitudinal change towards calculus and GeoGebra.

\section{PURPOSE OF THE STUDY}

This research study was expected to achieve the following:

$\checkmark$ It aimed to investigate the influence of the jigsaw co-operative learning strategy integrate with GeoGebra on learners' conceptual knowledge development and attitudinal change towards calculus and GeoGebra.

Specific objectives

$\checkmark$ To investigate experimental (EG) and comparison (CG) groups learners' conceptual knowledge (CK) development

$\checkmark$ To examine the influence of the jigsaw co-operative learning strategy integrate with GeoGebra on experimental group participants' attitudinal change towards calculus and GeoGebra.

\section{Research Questions}

This study responded to the following two research questions:

1. Does the jigsaw co-operative learning strategy integrate with GeoGebra better influence learners' conceptual knowledge (CK) development in intermediate calculus?

2. Does the jigsaw co-operative learning strategy integrate with GeoGebra influence attitude of experimental group participants' towards calculus and GeoGebra?

\section{Statement of the Hypothesis}

The first research question could be equivalently expressed in hypothetical statements as follows.

Null hypothesis 
$\mathrm{H}_{01}$ : Learners who learn intermediate calculus using the jigsaw co-operative learning strategy integrate with GeoGebra demonstrate the same conceptual knowledge (CK) as learners who learn without it.

Alternative hypothesis

$\mathrm{H}_{11}$ : Learners who learn intermediate calculus using the jigsaw co-operative learning strategy integrate with GeoGebra (JCLGS) demonstrate better conceptual knowledge (CK) as learners who learn without it.

\section{THEORETICAL FRAMEWORK}

This study influenced by Vygotsky's social constructivist cognitive development learning theory. This learning theory is the one compatible with co-operative learning strategy integrate with the technology learning environment. An understanding of it is very helpful to devise appropriate learning activities that enhance social learning in classroom instruction. To ensure the quality of the learning activities developed by the researcher, as one of the active learning strategies, the jigsaw co-operative learning strategy integrate with GeoGebra was considered and then applied in learners' calculus learning. The aim of using the JCLGS was to create a conducive active learning environment and then to increase learners' power to learn the desired conceptual knowledge of calculus (cognitive knowledge development). According to Amineh and Asl (2015), such kind of active learning strategy allows learners to share their previous experiences and knowledge through social interaction in the new learning environment. Social constructivism cognitive development learning theory also assists them to provide meaning to the knowledge being developed. This theory was applied for experimental group learners appropriately use the JCLGS in their calculus learning as one of the independent variable (ID) of the study. The other independent variable used by instructors to teach the comparison group learners is the traditional lecture method. The Jigsaw co-operative learning strategy JCLGS refers to a co-operative learning strategy undertaken through the interaction of learner-learner, learnerfacilitator, learner-learning material and learner-learning environment using the appropriate tools in GeoGebra for the attainment of group goals not obtained by working alone or competitively (Orey, 2010; Pilgrim, 2010). Learners' conceptual knowledge achievement scores of calculus and their responses to the fivepoints Likert scale attitude questionnaire are the dependent/problem (DV) variables of the study (Nenty, 2009).

In pedagogical principles, learners need to be exposed to several different learning activities rather than adhering to only one method to produce the desired cognitive knowledge. As most mathematics education research literature asserted, the traditional lecture method has not appropriately addressed learners' conceptual knowledge development of calculus. However, the active JCLGS played a very great role in addressing such learners learning problem of calculus in this study. Bransford and Brown (1999) supported this idea that technology-based learning is one kind of learning strategy capable of enhancing such multifaceted challenges. Bransford and Brown also described many new technologies are interactive. Even though it identified that the number of use of technology into mathematics learning has been rapidly increasing Highfield and Goodwin (2008), the situation was not supported by evidence-based on research literature. Lavicza (2010) states as technology use in mathematics learning have increased slowly. In contrast, there are great deals of research literature on the use of traditional lecture method as it has not been addressing learners' conceptual knowledge learning difficulty. However, in this twenty-first century, it is very essential intervening technology in every sphere of life as it has versatile functions. Especially, we all know that computer technology has been playing a very great role in mathematics and science education. In line with this, Bransford and Brown (1999); Kilicman, Hassan, and Husain (2010) have mentioned some of the importance of technology in learning in the following way if we use it appropriately. It allows learners to keep in touch with learning using a computer software package to create a new environment that integrates the content of the lesson and computer as a tool. They explore and experiment through it. It also helps learners to easily visualize and understand those concepts that challenged them in learning through the traditional lecture method. Besides that, they identify their mistake and correct responses when they try finding a solution for a calculus problem in developing conceptual knowledge. The knowledge generated continuously gets clearer \& clearer at the end of the day learners come up with a new idea. Technology integrated calculus learning could also create a conducive and interactive learning environment that encourages learners to associate theory with the objective world. Such learning atmosphere motivates learners to construct the desired knowledge in collaboration with their classmates and then give meaning individually for the derived knowledge. Furthermore, this learning environment paves the way for learning to be learner-centred that allows learners to actively be engaged to develop new knowledge. However, Koehler and Mishra (2009) suggest 
that as much as possible instructors or researchers should give special attention as to which technological tools to be chosen in advance that best suits for the learning of given content.

Vygotsky's social constructivism cognitive development learning theory of mathematics that sufficiently guided the theoretical framework of this study is discussed. It may now be of importance to start the discussion with some important general idea on how knowledge is perceived and developed. From the mathematics education philosophical school of thought, knowledge is viewed either as something out there that one can discover or one can construct it by his own during interaction with the environment (Cornelius \& Ernest, 1991). The second approach is more of a benefit in the study of human knowledge development as it sufficiently explains much of human knowledge, thinking and reasoning. Because of this view, the social constructivism cognitive development learning theory applied in this study as it allows learners to construct their knowledge through interaction with classmates. Limitation of learning resources like computers, large class size, learners' different learning styles, abilities, diverse interests and backgrounds in a given class had also been taken into account as factors to use the JCLGS. The involvement of several various processes and objects in generating say the concept limit and features of the intervention were also the other factors considered while designing. During the intervention, the developed learning activities by the researcher discussed by experimental group learners using the jigsaw co-operative learning strategy, integrate with GeoGebra as a tool (JCLGS). Each jigsaw group consisted of four or five learners. In so doing, this circumstance allowed the facilitators and learners to associate the social constructivism cognitive development learning theory with the JCLGS involved in the study that is strongly influenced by Lev Vygotsky's idea. Amineh and Asl (2015) have also shared the idea of describing a move from social constructivism to constructivism/individual learning. Mcmahon (1997) also theorized as culture and context mainly constitute social constructivism that enables learners to understand what occurs in society and then to construct knowledge. Amineh and Asl used such communal idea that is a move from social constructivism to constructivism learning in their research endeavour which is the principal contribution of (Vygotsky, 1980). Vygotsky states that learning for cognitive development can take place through social process emphasizing on dialogue. In other words, at the outset learning need to takes place socially to produce the intended knowledge development. Vygotsky's principles that entirely rely on more knowledgeable other (MKO) and the zone of proximal development (ZPD) play a very great role in cognitive development through social interaction. More knowledgeable other (MKO) refers to one who has better knowledge \& skill than others in the underlying learning environment. Siyepu (2013) defined the ZPD as "the difference what the learner can do without help and what a learner can do with help." The jigsaw co-operative learning strategy integrate with GeoGebra grounded in the social constructivism learning theory benefited the pedagogy in a way that allowed learners to be reflective, communicant, work and examine concepts in the group in developing the desired conceptual knowledge. The theory assumes that a learner could develop understanding, significance and meaning of the learning environment through interaction with peers and the instructor as facilitator (Amineh \& Asl, 2015; Orey, 2010). This means learning in the process of knowledge development could only be achieved through interaction with people mediated by the community and culture/context (Amineh \& Asl, 2015; Orey, 2010). Orey (2010) indicated that the development of cognition comes through social interaction. Amineh and Asl also mentioned that the problems of traditional teaching can be reduced through constructivism and social constructivism as suggested by Piaget, Vygotsky and Perkins. According to Vygotsky, in the first place factors like cultural, history and social interaction rather than individual construction could highly contribute to the success of cognitive development (Amineh \& Asl, 2015). Hoover (1996) also mentioned that the facilitators need to be considerate of learners' prior knowledge and experience in social interaction. It influences their new knowledge. Learning should not be passive rather active through which learners' can negotiate their understanding while experiencing the new learning situation. The fundamental and central roles that social interaction and community play in the development of cognition and in the process of "making meaning" are the other themes in Vygotsky's theory (Wertsch, 1985; Vygotsky, 1980). Because of the social constructivist perspective, knowledge development is a process that can be accomplished through interaction among learners, learners with the instructor and learners with the designed learning environment. Despite this idea, the instructor needs to be viewed as a facilitator, not as a teacher who is with multiple roles, such as consultant and coach (Cobb \& Bauersfeld, 1995). In line with this, it should be noted that the role of a teacher is lecturing that covers the subject matter whereas the role of a facilitator is guiding, helping, mentoring and supporting the learner to get into understanding of the content (Amineh \& Asl, 2015). In connection with this, Cobb and Bauersfeld (1995) stated as learners learn things passively when the instructor teaches whereas engage actively and learn things independently when the instructor facilitates, helps and guides them. This situation allows learners to be wholly engaged in the learning, the classroom environment to be democratic and interaction becomes crucial in learning (Gray, 
1997). Roth (1999) also forwarded that a learner needs to be allowed to interact with the surrounding on a social level. The social interaction environment allows a learner to make sense of others and construct knowledge. In conclusion, the purpose of the designed social constructivism learning environment should both support and challenge learners' thinking. Overall, the objective is to make learning to be learner-centred and then ends up with learners' to be independent thinker, problem solver and learner.

The theoretical framework could concisely be summarized as follows. It can be undertaken by examining the existing relationship among the philosophical assumptions such as ontology, epistemology and the social constructivism cognitive learning theory. The reason is that ontology is a branch of philosophy that studies about the nature of reality while epistemology deals with the nature of knowledge (Gelo, 2012; Gray, 2013; Saunders, Lewis, \& Thornhill, 2009). Also, the assumptions underlying social constructivism cognitive learning theory are based on the terms reality, knowledge and learning (Kim, 2001). Social constructivists have first established their assumptions on reality. They do not view it as something out there rather as it can be constructed through human activity (Amineh \& Asl, 2015; Orey, 2010). Also, Kukla (2013) argued as the properties of the world can be invented by members of a society or group together. Individual learners are the one who is responsible for constructing the desired knowledge through interaction with each other and the surrounding environment (Kim, 2001). Social constructivists assume learning as a social process (Amineh \& Asl, 2015; Orey, 2010). This means learning takes place when individuals interact with each other, with the facilitator, the learning material and environment. They believe that meaningful learning can take place through engaging individuals in social activities such as interaction and collaboration (Amineh \& Asl, 2015). In conclusion, the reality is not something out there that we need to discover instead it can be constructed through human social interaction. Knowledge is the result of human activity in which it can be constructed socially and culturally/contextually. Learning needs to be viewed as a social process that should be conducted by the active engagement of learners in the external factors through their interaction and collaboration in the surrounding environment. This means social learning tends to precede knowledge development (Orey, 2010). Therefore, these were the very crucial points that scaffold this study.

\section{RESEARCH METHODOLOGY}

This study employed the post-positivism quantitative methods approach as the research questions are hypothetical statements describing the cause-effect relationship between the JCLGS and learners' conceptual knowledge development. According to Creswell and Creswell (2017), this quantitative research study processed using deductive reasoning for which the hypothesis needs to be placed towards the beginning of developing the research proposal. The deductive scientific approach initially begins with a theory/hypothesis and then goes through data collection processes. At the of the day, the hypothesis should be tested to accept or reject or confirm or modify it (Castellan, 2010; Creswell \& Creswell, 2017; Gelo, 2012; Yilmaz, 2013). These were the main ingredients that lay foundations for the methods and drive their application.

\section{Research Design}

A non-equivalent pre-and post-test comparison group quasi-experimental design employed in the study is depicted as follows (Fraenkel, Norman, \& Wallen, 2009):

EG NR O $\mathrm{O}_{1} \mathrm{X}_{1} \mathrm{O}_{2}$

CG NR $\mathrm{O}_{1} \mathrm{X}_{2} \mathrm{O}_{2}$

where NR designates a non-random assignment of sample participants, $\mathrm{O}_{1}$ represents pre-test achievement scores of the experimental (EG) and comparison (CG) groups, $\mathrm{X}_{1}$ denotes the jigsaw co-operative learning strategy integrate with Geogebra used to nurture the experimental group (EG), $\mathrm{X}_{2}$ represents the traditional lecture method used to teach the comparison group (CG) and $\mathrm{O}_{2}$ denotes post-test achievement scores of the experimental (EG) and comparison (CG) groups. According to Fraenkel et al. (2009), the reason why this design was preferred is that the true experimental design is most often difficult to apply to human participants. The researcher does not have the power to control over all possible potentially confounding extraneous variables in using it. The other reason is that random assignment of learners in the same existing class/department into experimental and comparison groups is not ethical as they have already assigned by the Ministry of Education (MOE) to the two study areas/universities. Each university also assigned these learners based on their choice or without to the accessible departments. Because of this, at the outset, it was not necessitated applying random assignment in classifying individual participants instead of intact groups were employed. Therefore, as most mathematics education research literature suggests, for instance, Fraenkel et al. (2009), it is advisable 
to use the quasi-experimental design in such a situation. This research project designed to collect the essential data through the calculus classroom achievement test and the five-points Likert attitude scale questionnaire to respond to the research questions/hypotheses. This had been taken as the main reason for using the quasiexperimental design (Castellan, 2010). The other reason was that of the similarities of the two study areas/universities in geographical, academic, administrative and demographic factors.

\section{Research participants}

The research participants for both pilot and main study were the entire first-year undergraduate Mathematics, Physics, Chemistry and Statistics department learners in two public universities of Ethiopia who enrolled for an intermediate calculus.

\section{Sample (Pilot and Main Study)}

The sample size for the pilot study was 30, out of which 14 females and 16 males. They were randomly drawn from the intact 84 statistics learners. Ten were high achievers, 10 medium achievers and 10 low achievers. The age ranges from 18 to 21 . These samples were selected to conduct a reliability test for classroom achievement test. A sample size of 298 mathematics and science learners, out of which 106 females and 192 males drawn from one of the two study areas, who enrolled for intermediate calculus. The samples were used to conduct construct validity for learners' responses to the five-points Likert attitude scale questionnaire in the context of this study. The scales are labelled as $5=$ strongly agree, $4=$ agree, $3=$ neutral, $2=$ disagree and 1=strongly disagree. These scales adapted from Test of Science Related Attitudes (TOSRA) and Test of Mathematics Related Attitudes (TOMRA) which is a modification of TOSRA (Fraser 1981; Khine, 2013), developed by a distinguished Professor Barry J. Fraser in Macquarie University, Australia. Awang and Hamid (2015) reported the validity and reliability of this similar instrument.

The sample size for the main study was 150 , out of which 75 samples in the comparison group (CG) with 45 males and 30 females, whose age ranges from 18 to 25 . The remaining 75 samples make up the experimental group (EG), out of which 50 males and 25 females, whose age ranges from 18 to 24 . You may note that the ratios of the number of males to females in both groups are similar. Samples in both groups were almost in the same age range. These issues have also the most important places in using a non-equivalent pre-and posttest comparison group quasi-experimental design.

\section{Instrument}

The researcher-made classroom achievement test was one of the instruments used to collect quantitative data. Basics of limits, continuity, derivatives and integration have included in it. The questions have taken from the teaching materials such as modules, lecture notes and reference books. Special attention was paid to conceptual (CK) and procedural knowledge (PK) while designing and constructing it. The balanced and connected or iterative approach due to Kridler (2012); Chinnappan and Forrester (2014) applied as much as possible, to balance this two knowledge. They developed through going back and forth. The operational definitions of conceptual (CK) and procedural knowledge (PK) have also taken into consideration. The nature of the psychological construction or characteristics measured, referring to the nature of items in the test, ensured using Bloom's taxonomy of educational learning objectives theory (Fraenkel et al., 2009). In connection with this, Adebule (2009) suggests for instructors to use a combination of various test types in classroom achievement test at a time. It is used for easy management of the construction and administration of the intended test, as currently, the numbers of learners in universities are rapidly increasing all over the world. The classroom achievement test consisting of true/false (closed-ended), multiple-choice (closed-ended) and workout items (open-ended) employed by taking the remark and the assessment trend in Ethiopian public universities into consideration. The true-false items are twenty, the multiple-choice items thirty and the workout items five in number. They were used in the pilot and main study.

Learners' attitude towards the intermediate calculus/mathematics and GeoGebra questionnaire was the second instrument. Saunders et al. (2009) called such a survey questionnaire a delivery-and-collection questionnaire. It is administered by delivering the questionnaire to each research respondent by hand and then collected. The items were constructed based on five criteria as to how students view calculus/mathematics such as normality of mathematics (N), mathematics inquiry (I), adoption of mathematics (A), enjoyment of mathematics lessons (E) and learners' attitude towards calculus in learning it using the JCLGS. Awang and Hamid (2015) verified its validity and reliability in their research study. The validity and reliability of this instrument were also ensured in the context of the pilot study. It consisted of fifty items measured using the 
five points Likert-scale. Based on the twenty-eighty variables obtained from the pilot study, this instrument was used to measure experimental group learners' attitudinal change towards intermediate calculus over a semester.

\section{Ethical Considerations}

Before the researcher went through data collection, he applied for the College of Natural and Computational Sciences offices by specifying the purpose, nature, scope and methods. Accordingly, the Academic and Research Vice President Office of one university and Research and Technology Transfer Vice President Office of the other university wrote a letter showing permission to conduct this study to the Institute for Science and Technology Education (UNISA). Following this, the researcher requested ethical clearance from the College of Science, Engineering and Technology's (CSET) Research and Ethics Committee in UNISA. The University of South Africa (UNISA), where the researcher is enrolled for his $\mathrm{PhD}$, has given the ethics approval grant for the study on the date 20/07/2016, as it has met all the ethical requirements as stipulated by the university. When the study began, the facilitators informed research participants as pre-test and posttest will be administered and also intervention will be undertaken. In so doing, they have notified them that the information they are providing is very essential to obtain the appropriate results. The participants were also advised by their instructors not to hesitate as something occurs that may cause them harm. This means confidentiality ensured at every step of the study. Pre, during and post data collection, they are identified by a code to guarantee anonymity.

\section{Validity and Reliability}

\section{Overview}

The validity of a research instrument is one of the most common and important features of research used to estimate what the instrument is supposed to measure (Fraenkel et al., 2009; Johnson \& Christensen 2014; Saunders et al., 2009). Generally, it is classified into internal and external validity. The internal validity is used to ensure correct inferences based on the collected data as this study designed to examine the cause-andeffect relationship. According to Fraenkel et al. (2009), it can be validated through content-related, criterionrelated and construct related evidence. Nevertheless, content validity is the most appropriate device for the classroom achievement test. Also, Fraenkel et al. (2009) suggest that content-related evidence of validity need to be evaluated by the subject experts. When we select them, their educational status, skill and experience should be considered as much as possible. As Fraenkel et al. (2009) indicated, they must check the level of difficulty of sample questions and whether the items based on the objective of the study and the proposed definition of measurements. The content, the clarity of printing, the format and appropriateness of the language of the instrument are also evaluated. These things are mostly assessed by face validity techniques. Similarly, the relationship between scores obtained using the researcher made-test and scores obtained from one or more other instruments could be ensured using the criterion-related evidence. The correlation coefficient index (r) is one of the statistical tools used for analyzing it. The construct-related evidence of validity can be verified using Bloom's taxonomy of educational learning objectives theory (Fraenkel et al., 2009). Validity evaluation of learners' attitude questionnaire towards calculus/mathematics quite resembles the classroom achievement test.

The reliability of a research instrument is the other most import aspect used together with the concept validity. According to Fraenkel et al. (2009), the reliability of an instrument assists the researcher to ensure the consistency of response scores from one administration to another or from one set of items to another. As described in Yimer (2016), test-retest, equivalent form and internal consistency methods are the main types of the level of reliability testing tools. However, Yimer (2016) stated that the standard error of measurement introduced by equivalent-forms reliability or internal consistency reliability method is small. Despite that and lack of resources, the reliability of the classroom achievement test of this study estimated using the internal consistency method (Yimer, 2016). It carried out by administering a single test only once to a group of participants. The reliability coefficient calculated by considering the correlation between the item score and the total test score (Kiliyyani \& Sivaraman, 2016). The internal consistency reliability of both multiple-choice and true-false items have been checked using the Kuder-Richardson Formula 21 (Kuder \& Richardson, 1937). The reliability coefficient of workout items needs to be computed by Cronbach's alpha (a) coefficient whose value must be at least 0.7 (Arbin et al., 2014; Kuder \& Richardson, 1937; Zulnaidi \& Zakaria, 2012) for classroom achievement test. 


\section{Content/Face validity of the classroom achievement test and learners' attitude questionnaire towards Calculus}

The researcher applied to the head of the mathematics department in which some of the instructors to evaluate content validity. He applied by specifying the names giving due emphasis on their experience and skill. In so doing, those benchmark points stated by Fraenkel, Norman and Wallen have been indicated to help evaluators be on the right track. In the beginning, they forwarded minor comments on the instruction part of the true/false items such as quotation marks and misspelt words. They also identified what each question measures learners' conceptual (CK) or procedural knowledge (PK). They also put quite similar comments on the instruction part of the multiple-choice items. The stem, the distractors, the correct answers, typo errors, improper mathematical symbols or notations and whether each question represents conceptual (CK) or procedural (PK) had also been evaluated. Finally, the workout/open-ended items were assessed in quite similar to the two parts. Overall, they also checked whether the items have been constructed based on the syllabus or not. Just as with the first instrument, the researcher also arranged the environment in the way that the second instrument to be evaluated individually to get a very detailed comment. At the end of the day, the researcher has gone through giving a close looks at the comments suggested and then corrected them for research participants in the main study better understand and thereby to obtain the appropriate data.

\section{Overview of item analysis of true-false, multiple-choice and work-out items}

The internal consistency technique employed to conduct item analysis that reveals the correlation between item score and test score, and the reliability coefficient estimate of the entire test score. Four item analysis indices such as item difficulty level $(\mathrm{P})$, discrimination index $(\mathrm{D})$, point-biserial coefficient $\left(\mathrm{r}_{\mathrm{pbi}}\right)$ and reliability coefficient index ( $r_{\text {test }}$ ) were used (Ding \& Beichner, 2009; Kiliyanni \& Sivaraman, 2016). The item difficulty level ranges from $0 \%$ to $100 \%$ or 0.0 to 1.0 (Boopathiraj \& Chellamani, 2013). The ideal value (midway between chance and a perfect score) for the true-false item is 0.75 . Similarly, the ideal value for the multiple-choice item is 0.6 . The item with P-value above 0.9 is an extremely easy one. In such a case, the item needs to be revised by the researcher based on the purposes that he/she sets in advance. The item with $\mathrm{P}$-value below 0.3 is a very difficult one. In such a case also, the item needs to be reviewed for possible confusing language and poorly constructed items. Such items may be removed from subsequent examinations. Identification of an area for re-instruction can also be made. According to Ding and Beichner (2009), the acceptable item difficulty value ranges from 0.3 to 0.9 for practical utility. Ding and Beichner also indicated the standard value for item discrimination could be greater than or equal to 0.30 . The higher the value the better the generated item is. According to Kline (1986), the acceptable point-biserial coefficient value is greater than or equal to 0.2. The higher the value the better the item is. As Costa, Oliveira, and Ferrão (2009); Ding and Beichner (2009) studied, the most appropriate statistical tool used to estimate the reliability coefficient index is the KuderRichardson Formula 21. It measures the internal consistency of a test. An acceptable value is greater than or equal to 0.7 (Kuder \& Richardson, 1937). These indices improve the quality and accuracy of the objectively scored tests.

Workout items in mathematics classroom achievement test are considered as one of the subjectively scored tests. Methods of analyzing its internal consistency are quite different from that of the objectively scored tests even though both measures aimed at addressing the same issue. The researcher and another instructor (raters) corrected it based on a common answer key. These instructors had almost equivalent experience and taught a similar course in that academic semester. The purpose was to reduce personal biases. When the classroom achievement scores represent a continuous scale of measurement and involve two raters, the consistency and stability (agreement) of the scores can be ensured through inter-rater reliability and interrater agreement measures. Liao, Hunt, and Chen (2010) indicated that inter-rater reliability can be measured by the Pearson Product Moment Correlation. Graham, Milanowski, and Miller (2012) pointed-out that the intra-class correlation coefficient (ICC) measures the inter-rater agreement. According to Graham et al. (2012); Liao et al. (2010), the inter-rater reliability index ranges from - 1 to 1 and the inter-rater agreement index ranges from 0 to 1 .

\section{Item analysis of true-false items}

The item difficulty index and the average item difficulty level were found to be in the acceptable range [0.30, 0.90] (Boopathiraj \& Chellamani, 2013; Ding \& Beichner, 2009). The item discrimination index of the twelve items was found in the standard range [0.30,1.00] while indices of the eight items were not in that range. However, as item 14 came up with a negative item discrimination index, it rejected in the main study. 
Table 1. Descriptive Statistics and Item Analysis Results for True-false and Multiple-choice items in the Pilot Test

\begin{tabular}{lccccccc}
\hline & $\mathbf{n}$ & $\mathbf{M}$ & SD & $\begin{array}{c}\text { Average Item } \\
\text { Difficulty Index }\end{array}$ & $\begin{array}{c}\text { Average Item } \\
\text { Discrimination }\end{array}$ & $\begin{array}{c}\text { Average } \\
\text { Reliability Index } \\
\text { of Item Score }\end{array}$ & $\begin{array}{c}\text { Average } \\
\text { Reliability Index } \\
\text { of Total Score }\end{array}$ \\
\hline True-false & 30 & 14.30 & 3.33 & 0.72 & 0.38 & 0.26 & 0.7 \\
\hline Multiple-choice & 30 & 13.37 & 7.30 & 0.45 & 0.61 & 0.46 & 0.9 \\
\hline
\end{tabular}

Table 2. Descriptive Statistics, Inter-rater Reliability and Inter-rater Agreement Results for Work-out Items in Pilot Study

\begin{tabular}{|c|c|c|c|c|c|c|c|c|}
\hline & & \multicolumn{2}{|c|}{$\mathbf{M}$} & \multicolumn{2}{|c|}{ SD } & \multicolumn{3}{|c|}{ Pearson's Product $\begin{array}{c}\text { Intra-class Correlation } \\
\text { Coefficient (ICC) }\end{array}$} \\
\hline Question & $\mathbf{n}$ & Rater 1 & Rater 2 & Rater 1 & Rater 2 & Moment Index & Single Measure & Average Measure \\
\hline $\mathrm{Q} 1$ & 30 & 1.28 & 1.18 & 1.16 & 1.13 & 0.984 & 0.981 & 0.990 \\
\hline $\mathrm{Q} 2$ & 30 & 0.87 & 0.82 & 0.85 & 0.83 & 0.984 & 0.982 & 0.991 \\
\hline Q3 & 30 & 1.57 & 1.45 & 1.27 & 1.23 & 0.981 & 0.976 & 0.988 \\
\hline $\mathrm{Q} 4$ & 30 & 1.00 & 0.97 & 1.00 & 0.99 & 0.992 & 0.992 & 0.996 \\
\hline Q5 & 30 & .57 & .52 & 1.22 & 1.18 & 0.987 & 0.986 & 0.993 \\
\hline
\end{tabular}

The seven items with low item discrimination values have been revised. The average item discrimination index was 0.38 and it is a satisfactory value. The point-biserial correlation coefficient for more than half of the items belonged to $[0.20,1.00]$. These values for around nine items were low. The average point-biserial correlation coefficient index was 0.26 and it is acceptable. The reliability coefficient index of the entire test score was found to be 0.7. The items are the most applicable items for group assessment (Kuder \& Richardson, 1937).

\section{Item analysis of multiple-false items}

The item difficulty index of seven items was below the lower limit (Boopathiraj \& Chellamani 2013; Ding $\&$ Beichner 2009). The item difficulty indices of twenty-three items lie in the standard range [0.30, 0.90]. As compared to the true-false items, the multiple-choice contain many difficulty items. The average item difficulty index was 0.45 and it is an acceptable value. The item discrimination indices of five items were below the lower limit. The item discrimination indices of twenty-five items were in the standard range [0.30, 1.00]. The item discrimination indices of two items were 0 . They did not differentiate high achievers from low achievers. Due to this, they have been removed. The average discrimination index was 0.61 . This value is acceptable. The point-biserial correlation coefficient indices of five items lie in the standard range [0.20, 1.00]. The item discrimination indices of two of them were 0 . The average point-biserial correlation coefficient index was 0.46 . This value is acceptable. The reliability coefficient index of the entire test score was found to be 0.91 . It is an excellent value. This statistical analysis suggests to the researcher that the test was the most likely selfsufficient instrument to be employed in the main study. Table 1 depicts the results of the descriptive statistics and item analysis for both the true-false and multiple-choice items.

\section{Item analysis of work-out items}

As depicted in Table 2, we can find that the mean and standard deviation rates for both raters on workout items were nearly the same. Almost no bias was made in correcting these questions. Their inter-rater reliability indices were very high. These results were also in support of the above idea as the raters' rates on the same learner are consistent. The inter-rater agreement index for each item was found to be very high. This means each value is in the acceptable range. Therefore, these measures tell as these items were suitable to be employed in the main study. The Cronbach's alpha reliability coefficient value of the average scores of the two raters was observed to be 0.87 and it is an acceptable medium value.

\section{Construct validity of learners' attitude towards Calculus and GeoGebra}

The collected data on survey questionnaire from 298 mathematics and science learners in one of the two research areas was input into SPSS 23. It was carried out to identify those factors that dominate learners' attitude out of the five dimensions through multivariate statistical analysis techniques. The mean values of each variable on entered data were a bit greater than or equal to 3.00. This observation had an important place to use exploratory factor analysis (EFA) (Cohen, Manion, \& Morrison, 2007; Demircioglu, Aslan, \& Yodigaroglu, 2014). This means all variables can contribute to what the researcher looks for in the extraction of factors. As the variables were independent, the construct validity ensured using the principal component 
Table 3. Kaiser-Mayer-Olkin (KMO) and Bartlett's test of sphericity

\begin{tabular}{cccc}
\hline Kaiser-Meyer-Olkin & \multicolumn{2}{c}{ Bartlett's Test of Sphericity } \\
\cline { 3 - 4 } Measure of Sampling Adequacy & Approx. Chi-Square & df & Sig. \\
\hline .849 & 6654.583 & 1225 & .000 \\
\hline
\end{tabular}

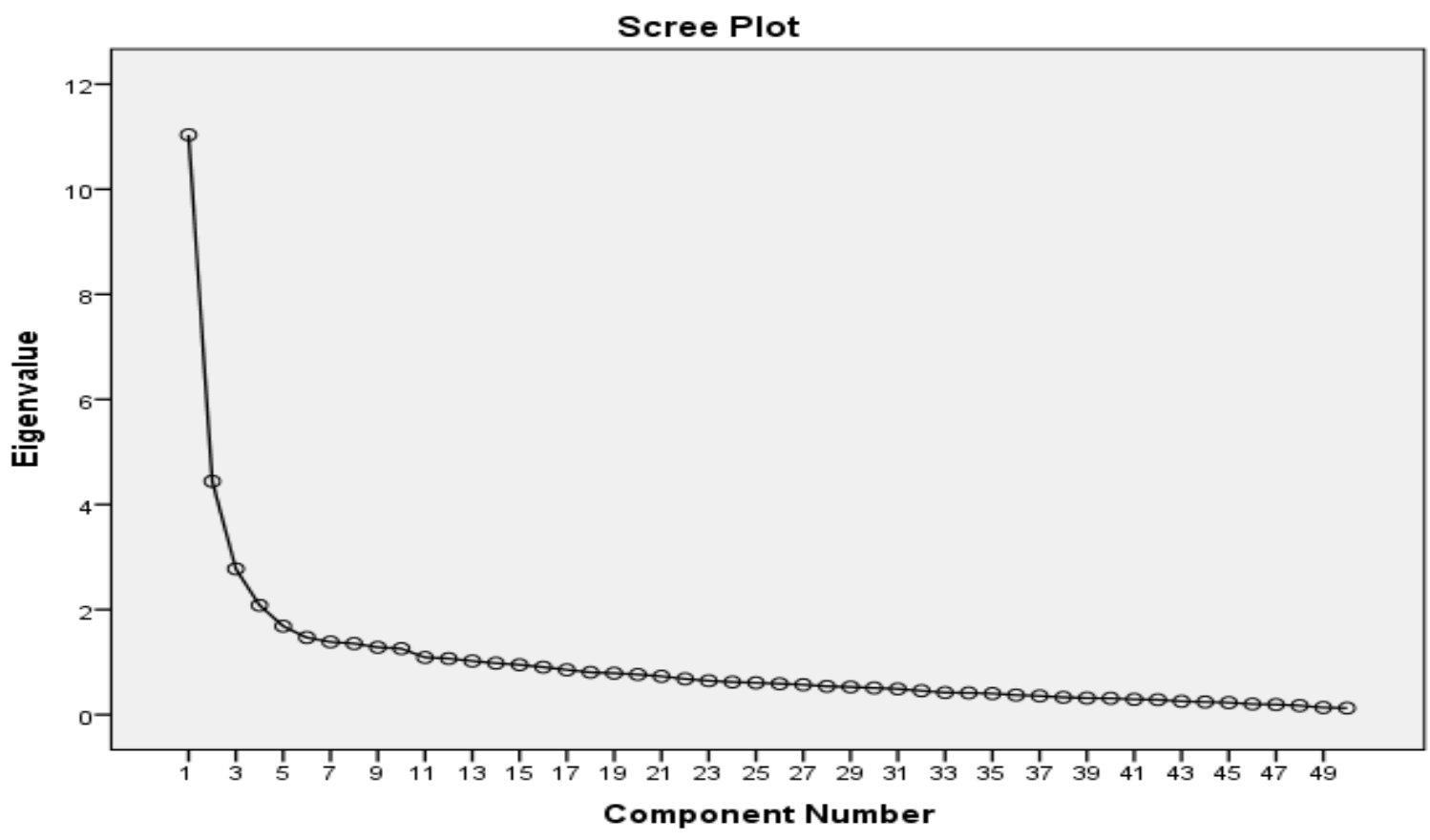

Figure 1. Scree Plot Graph

factor analysis (PCFA) with varimax rotation. The purpose was to determine the group in which the subcriterion/variable belongs (reducing variables). Cohen et al. (2007); Yong and Pearce (2013) suggest that large sample size needs to be given special attention in factor analysis. The most research literature on cognitive and behavioural sciences has indicated that the sample size has to be sufficiently large. For instance, Yong and Pearce (2013) reported that the ratio of the number of respondents to variables should be at least 10:1. If survey research involves 20 variables, then the number of participants should be at least 200 . The ideas briefed in Demİrcíğlu et al. (2014) were also quite similar to this. Thus, the number of respondents (298) involved in this research project is considered to be medium-sized. When the sample size is small or medium level, Bartlett test of Sphericity and Kaiser-Mayer-Olkin Measure (KMO) are two very crucial statistical tests (Demircioglu et al., 2014) used to determine whether the data are appropriate for factor analysis or not. They encourage you to access the suitability/conformity of subscales. Cohen et al. (2007) suggest that data are convenient for factor analysis whenever the significant level ( $p$-value) of Bartlett's test of sphericity test is at the 0.05 levels or better. Also, the Kaiser-Mayer-Olkin (KMO) value is greater than or equal to 0.6. Table 3 displays Bartlett's test of sphericity test and Kaiser-Mayer-Olkin (KMO) values.

The results of Bartlett's Test of Sphericity and Kaiser-Mayer-Olkin Measure of Sampling Adequacy (KMO) depicted in Table 3 met the required assumptions for factor analysis. Demircioglu et al. (2014); Yong and Pearce (2013) also suggest as the other reliability aspect of the collected data needs to be verified based on the relationship between the scale items. This value can be determined by Cronbach's alpha reliability coefficient. It was found to be .89 and it is a highly acceptable value. Therefore, the main study was kept on.

The concepts of the scree plot and Eigenvalues play an important role in the process of factor analysis. According to Cohen et al. (2007); Demircioglu et al. (2014); Yong and Pearce (2013), they can be used to determine the number of underlying/latent factors retained. Kaiser's criterion is one of the criteria that is used based on Eigenvalues greater than or equal to 1. The graph of the scree plot with Eigenvalues against the component/factor numbers is shown in Figure 1.

Yong and Pearce (2013) states that the judgment as to the cut-off point of factor loadings and the number of factors is usually left for the researcher to use his professional skill. Despite that, the cut-off point for factor 
INT ELECT J MATH ED

Table 4. Three Factors Influencing Learners' Attitude

\begin{tabular}{|c|c|c|c|}
\hline Statement of the Scale & $\begin{array}{l}\text { Normality } \\
\left(\mathbf{F}_{1}\right)\end{array}$ & $\begin{array}{l}\text { Enjoyment } \\
\left(\mathrm{F}_{2}\right)\end{array}$ & $\begin{array}{c}\text { Attitude towards } \\
\text { calculus and } \\
\text { GeoGebra }\left(\mathrm{F}_{3}\right)\end{array}$ \\
\hline Mathematicians are about as fit and healthy as other & .604 & & \\
\hline Mathematicians do not have enough time to spend with their families & .418 & & \\
\hline Mathematicians like sports as much as other people do & .413 & & \\
\hline Mathematicians are less friendly than other people & & .766 & \\
\hline Mathematicians can have a normal family life & .489 & & \\
\hline Mathematicians do not care about their working conditions & .512 & .488 & \\
\hline Mathematicians are just as interested in art and music as other people are & .634 & & \\
\hline $\begin{array}{l}\text { If you met a mathematician, he/she would probably look like anyone else you } \\
\text { might meet }\end{array}$ & .678 & & \\
\hline $\begin{array}{l}\text { I enjoy working with calculus problems through learning integrated with } \\
\text { GeoGebra as a tool }\end{array}$ & & & .410 \\
\hline $\begin{array}{l}\text { GeoGebra as a tool in calculus learning cannot benefit in visualizing concepts } \\
\text { and developing knowledge }\end{array}$ & .634 & & .568 \\
\hline $\begin{array}{l}\text { Representing calculus concepts in multiple ways using GeoGebra as a tool } \\
\text { enhances your learning }\end{array}$ & & & .405 \\
\hline $\begin{array}{l}\text { I do not like learning calculus linked with real-life problems using GeoGebra as } \\
\text { a tool }\end{array}$ & .601 & & .491 \\
\hline $\begin{array}{l}\text { Learning calculus using GeoGebra as a tool makes knowledge of concepts and } \\
\text { procedures/steps to be easily understood }\end{array}$ & & & .591 \\
\hline GeoGebra are not good tools for mathematics/calculus learning & & & .600 \\
\hline $\begin{array}{l}\text { Learning calculus using GeoGebra as a tool reduces my Mental work (cognitive } \\
\text { load) }\end{array}$ & & & .540 \\
\hline Learning calculus with the aid of GeoGebra as a tool cannot economize time & & & .519 \\
\hline GeoGebra is a valuable tool for calculus learning & & & .543 \\
\hline $\begin{array}{l}\text { Using GeoGebra as a tool cannot encourage creative learning environment of } \\
\text { calculus }\end{array}$ & & & 400 \\
\hline Mathematics/calculus lessons are fun & .415 & & \\
\hline I do not like mathematics/calculus lessons & & .544 & \\
\hline Universities should have more mathematics/calculus lessons each week & .513 & & \\
\hline Mathematics/calculus lessons bore me & .472 & .525 & \\
\hline Mathematics/calculus is one of the most interesting courses in the university & .513 & & \\
\hline Mathematics lessons are a waste of time & & .690 & \\
\hline I really enjoy going to classes where mathematics/calculus lessons are presented & .624 & & \\
\hline The material (content) covered in mathematics/calculus lessons is uninteresting & & .579 & \\
\hline I look forward to mathematics/calculus lessons & .493 & & \\
\hline I would enjoy university more if there were no mathematics/calculus lessons & & .552 & \\
\hline Eigen values & 8.01 & 4.14 & 5.067 \\
\hline Percentage of Variance Explained & $0.16(16 \%)$ & $0.083(8.3 \%$ & $.101(10.1 \%)$ \\
\hline Cronbach's alpha coefficient & .806 & .813 & .815 \\
\hline Total Cronbach's alpha coefficient & .84 & & \\
\hline Total Percentage of Variance Explained & 34.43 & & \\
\hline
\end{tabular}

loadings in the pilot study was estimated to be 0.4 . The number of factors obtained as five by simply looking at the scree plot graph. They contain $45 \mathrm{sub}$-criteria/variables. The fifth factor/point where the graph changes its concavity from left to right is an inflexion point. The left of this point the graph is concave upward and to the right, it is concave downward. The Eigenvalues of the factors 1, 2, 3, 4 and 5 were respectively, 11.993, 6.754, 6.190, 2.09 and 2.04. The percentage of variance explained by each of the factors is $23.98,13.51,12.38$, 4.18 and 4.08. The total percentage of variance explained was 58.13. The Cronbach's alpha reliability coefficients of each of the factors/internal consistency were $.792, .783, .797, .813$ and .815 . The total Cronbach's alpha reliability coefficient was .89 . The researcher by making thorough examination further reduced the variables based on five factors. Three factors predominantly influenced learners' attitude. They are normality of mathematics (N), enjoyment of mathematics lessons (E) and learners' attitude towards calculus and GeoGebra. These findings were quite similar to (Awang, Ilias, Che Hussain, \& Mokhtar 2013). There have been twenty-eight variables with their corresponding factor loadings. These things remind the researcher to identify learners' positive or negative attitudes towards calculus and thereby to devise the appropriate learning strategies that help to take remedial actions for a given lesson. This, in turn, will make the learning of intermediate calculus interesting, satisfactory and easy for learners. As to this research, this pilot test greatly benefited the application of the intervention (JCLGS) in the process of data collection of the main study. The results obtained from the data analysis on the scale in terms of factor loadings, Cronbach's alpha reliability coefficients, Eigenvalues and variance are depicted in Table 4. 


\section{Intervention}

In the beginning, the researcher conducted training with two instructors for one week who have Masters Degrees in Mathematics. They served 7 and 24 years in teaching. These instructors were skilful of manipulating GeoGebra. The training was based on all about the learning activities on calculus, the JCLGS and GeoGebra. The active JCLGS grounded in Vygotsky's social constructivism cognitive development learning theory designed to identify whether these learning activities address learners' learning challenges of calculus or not. Statistics and chemistry departments from both research areas were randomly selected. The researcher requested the head of the Department of Mathematics at his home university. The instructor served 24 years assigned for statistics learners and the other one who served 7 years assigned for chemistry learners. These intact learners from both departments constitute the experimental group (EG). The instructor served 26 years assigned for statistics learners and the other who served 9 years assigned for chemistry learners in the second research area. These learners from both departments constitute the comparison group (CG). As soon as 'day one class one' began, the instructors assigned for the intervention gave course outline and training on all about basics of GeoGebra. This carried out for 24 hours for 12 weeks in the laboratory class ( 2 hours for one laboratory class in a week). Side-by-side, these learners learnt in their normal class using the traditional lecture method. Learners in the second university learnt the same course in their normal and tutorial class using the traditional lecture method. After two weeks of learning, pre-test on conceptual (CK), procedural (PK) and content (COK) knowledge administered for both intact group learners by their respective instructors. Three hours allotted for the pre-test. Only the experimental group learners took learners' attitude towards calculus questionnaire in this same session.

The intact experimental group learners proceeded to learn calculus using the JCLGS/intervention. During the intervention, these learners supplied with fundamental functions which help them to pay special attention in their interaction. Note and worksheets on every four chapters, two tests, one home assignment and various sample questions on the classroom achievement test also provided to them. The intact comparison group learners used only the traditional lecture method in both normal and tutorial classes until the end of the semester. Nearly the end of the semester, learners in both universities sat for their post-test that is quite equivalent to the pre-test for three hours. As with the pre-test, only the experimental group learners took learners' attitude towards calculus questionnaire. The reason why this intervention conducted is to nurture experimental group learners and then to examine the influence of it on their conceptual knowledge development of calculus as compared to the traditional lecture method.

Figure 2 depicts one of the integration (area) problems presented in the intervention that learners tried finding solution based on the graphs of $f(x)=x^{3}, g(x)=8 x$ and $h(x)=8$.

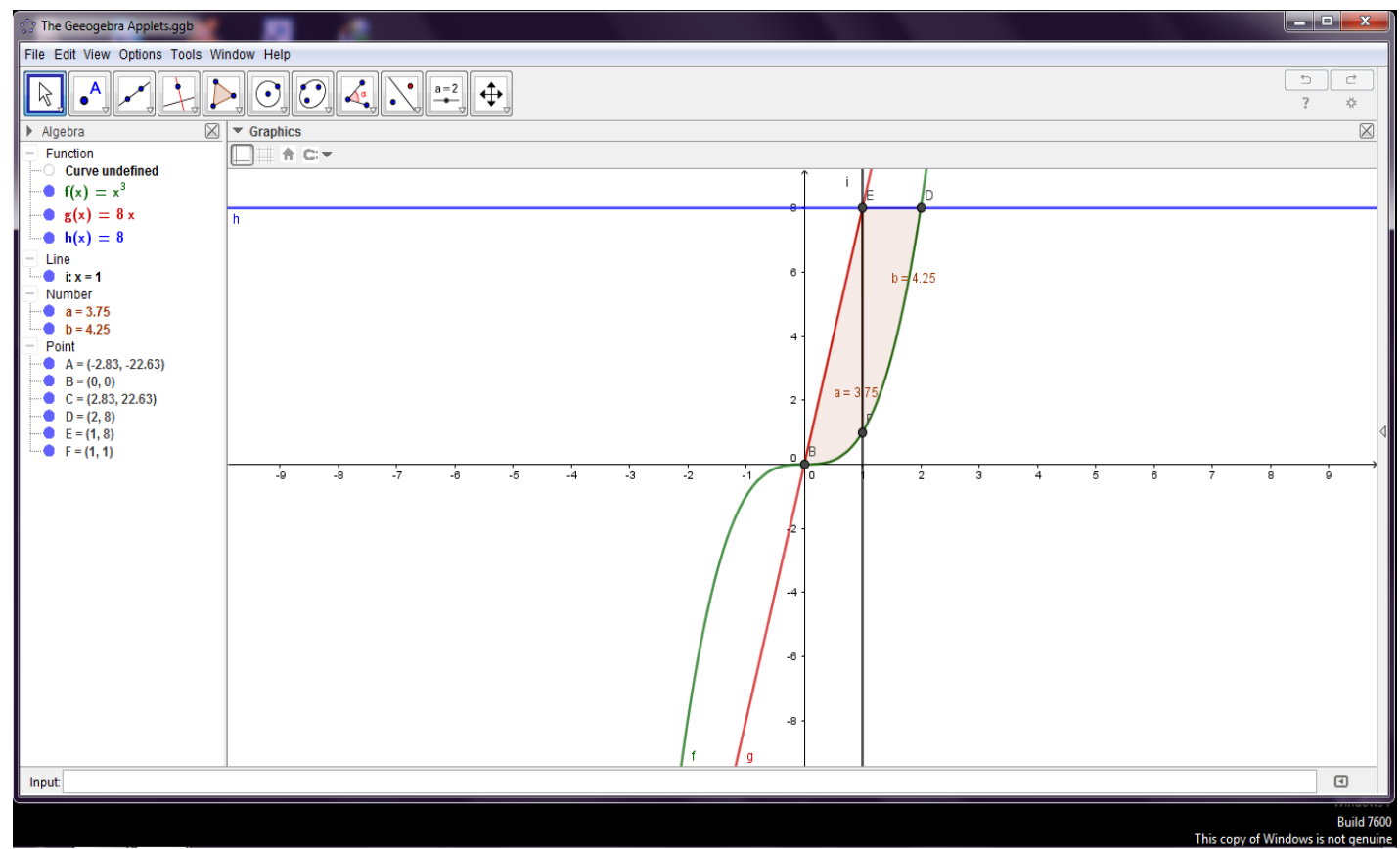

Figure 2. One of the Area Problems that Learners' Attempted in the Mathematics Laboratory/Tutorial Class 


\section{DATA COLLECTION PROCEDURES}

This study utilized the most common instruments, the calculus classroom achievement test and attitude questionnaire. It pilot tested to ensure reliability and validity. Accordingly, the researcher has corrected it to be better suited for the main data collection process. This means the general, as well as the specific instruction, was clearly stated. The researcher also tried to make the language simple so that the research participants would easily understand. The misspelt words, phrases, printing size and sentences were edited. Before administration of the instrument for the main study, the researcher and data collectors discussed those factors that affect the data like weather, classroom size and facilities such as chairs and desks. The researcher and data collectors also tried their best for all of these pertinent factors and related issues such as participants' scores not related to their grades to be adjusted based on the objective reality of the university. The pre-and post-test on instruments completed by the research participants. The research participants' responses corrected by the researcher and data collectors. Data on learners' attitude towards calculus questionnaire were prepared, described and organized by the researcher.

\section{Data Preparation for Analysis}

The calculus classroom achievement test consisted of three parts (research instrument one). Each measures learners' conceptual (CK), procedural (CK) and content knowledge (COK) as dependent variables. The first part consists of 15 conceptual (CK), 2 procedural (PK) and 20 content knowledge (COK). The second part consists of 26 conceptual (CK), 18 procedural (PK) and 60 content knowledge (COK). The third part consists of 4 conceptual (CK), 8 procedural (PK) and 20 content knowledge (COK). Conceptual calculated out of $45 \%$, procedural $28 \%$ and content knowledge $100 \%$.

Learners' attitude towards calculus questionnaire (research instrument two) consisted of 28 five points Likert scale. Fifteen statements are positively worded and 13 negatively worded. It was used to measure an experimental group (EG) learners' attitudinal change towards calculus. Learners' responses for the positively worded statements entered into SPSS 23.0 without making any transformation. The negatively worded statements transformed such as 1 to 5,2 to 4 and 3 remains there.

\section{DATA ANALYSIS}

Data were conducted on learners' classroom achievement test scores and their attitude responses towards calculus at two points in the period on a semester-based academic year. According to Saunders et al. (2009), when interval/ratio scale data are collected in this way, the t-test is the most appropriate and widely used parametric statistic to test changes over time. Because of this, data were analyzed by using descriptive, an independent-samples t-test and Two-Way ANOVA for repeated measures analysis procedures.

\section{STATISTICAL RESULTS AND INTERPRETATION}

The second research question was not a hypothetical statement. It answered by using descriptive analysis as data measured by an ordinal scale. Before carrying-out data analysis, it is important to make awareness about the Cronbach's alpha reliability coefficient values. As depicted in Table 5, the pre-test Cronbach's alpha reliability coefficient values are all in the acceptable range. Two of them are very high values and the other one is medium. The overall attitude value is also very high. This implies the pre-test results were consistent. As with the pre-test, the post-test Cronbach's alpha values are acceptable. The results of the post-test data were also stable.

As shown in Table 6, except for one mean value, the mean value of each variable in the pre-test was below the neutral scale. The weighted mean was less than the neutral scale. In the pre-test, learners did not view mathematics as normal as other subjects. In contrast, the mean value of each variable in the post-test was greater than the neutral scale. This was most likely due to the effect of the influence of the JCLGS in learners' calculus learning.

Table 5. Cronbach's Alpha Reliability Coefficients

\begin{tabular}{lrr}
\hline \multirow{2}{*}{ Criterion of Attitude } & \multicolumn{2}{c}{ Cronbach's Alpha (a) } \\
\cline { 2 - 3 } Normality & Pre-test & Post-test \\
\hline Enjoyment & .911 & .803 \\
\hline Attitude towards calculus and GeoGebra & .947 & .844 \\
\hline Overall Attitude & .874 & .793 \\
\hline
\end{tabular}


Table 6. Descriptive Statistics for Experimental Group Normality Attitude

\begin{tabular}{|c|c|c|c|c|}
\hline \multirow{2}{*}{ Normality Attitude } & \multicolumn{2}{|c|}{ Pre-test } & \multicolumn{2}{|c|}{ Post-test } \\
\hline & M & SD & M & SD \\
\hline Mathematicians are about as fit and healthy as other people & 2.83 & .934 & 3.79 & 1.244 \\
\hline Mathematicians do not have enough time to spend with their families & 2.25 & .960 & 4.58 & 1.071 \\
\hline Mathematicians like sports as much as other people do & 2.46 & .838 & 4.62 & .863 \\
\hline Mathematicians are less friendly than other people & 2.56 & .977 & 4.58 & 1.045 \\
\hline Mathematicians can have a normal family life & 2.53 & .978 & 4.62 & .941 \\
\hline Mathematicians do not care about their working conditions & 4.18 & .565 & 4.45 & .872 \\
\hline Mathematicians are just as interested in art and music as other people are & 2.47 & .855 & 4.53 & 1.100 \\
\hline If you met a mathematician, he/she would probably look like anyone else you might meet & 2.24 & 1.204 & 4.21 & 1.087 \\
\hline Weighted mean & 2.69 & & 4.42 & \\
\hline
\end{tabular}

Table 7. Descriptive Statistics for Experimental Group Enjoyment Attitude

\begin{tabular}{|c|c|c|c|c|}
\hline \multirow{2}{*}{ Enjoyment Attitude } & \multicolumn{2}{|c|}{ Pre-test } & \multicolumn{2}{|c|}{ Post-test } \\
\hline & M & SD & M & SD \\
\hline Mathematics/calculus lessons are fun & 2.81 & .898 & 4.67 & .582 \\
\hline I do not like mathematics /calculus lessons & 2.43 & .962 & 4.50 & 1.113 \\
\hline Universities should have more mathematics /calculus lessons each week & 2.24 & .459 & 4.33 & 1.113 \\
\hline Mathematics/calculus lessons bore me & 1.74 & 1.501 & 4.24 & 1.316 \\
\hline Mathematics/calculus is one of the most interesting courses in the university & 3.03 & .374 & 4.49 & 1.088 \\
\hline Mathematics/calculus lessons are a waste of time & 2.53 & 1.150 & 4.74 & .531 \\
\hline I really enjoy going to classes where mathematics/calculus lessons are presented & 2.49 & 1.007 & 4.19 & 1.328 \\
\hline The material (content) covered in mathematics/calculus lessons is uninteresting & 1.72 & 1.416 & 4.21 & 1.087 \\
\hline I look forward to mathematics/calculus lessons & 2.06 & 1.174 & 4.33 & .712 \\
\hline I would enjoy university more if there were no mathematics/calculus lessons & 2.36 & .810 & 3.97 & 1.244 \\
\hline Weighted mean & 2.34 & & 4.36 & \\
\hline
\end{tabular}

Table 8. Descriptive Statistics for Experimental Group Attitude towards calculus and GeoGebra

\begin{tabular}{|c|c|c|c|c|}
\hline \multirow{2}{*}{ Attitude towards Calculus and GeoGebra } & \multicolumn{2}{|c|}{ Pre-test } & \multicolumn{2}{|c|}{ Post-test } \\
\hline & M & SD & M & SD \\
\hline $\begin{array}{l}\text { I enjoy working with calculus problems through learning integrated with GeoGebra as a } \\
\text { tool }\end{array}$ & 3.04 & .426 & 4.64 & .512 \\
\hline $\begin{array}{l}\text { Using GeoGebra as a tool in calculus learning cannot benefit in visualizing concepts and } \\
\text { developing knowledge }\end{array}$ & 3.10 & .653 & 4.50 & .872 \\
\hline $\begin{array}{l}\text { Representing calculus concepts in multiple ways using GeoGebra as a tool enhances your } \\
\text { learning }\end{array}$ & 2.99 & .205 & 3.79 & 1.244 \\
\hline I do not like learning calculus linked with real-life problems using GeoGebra as a tool & & & & \\
\hline $\begin{array}{l}\text { Learning calculus using GeoGebra as a toolmakes knowledge of concepts and } \\
\text { procedures/steps to be easily understood }\end{array}$ & 3.07 & .306 & 4.6 & .863 \\
\hline ca is not a good tool for calculus learning & 3.25 & .80 & 4.58 & 1.045 \\
\hline a tool reduces & 3.22 & .63 & 4.62 & \\
\hline $\begin{array}{l}\text { Learning calculus with the aid of a computer softw: } \\
\text { time }\end{array}$ & 1.71 & 1.347 & 4.57 & .709 \\
\hline GeoGebra is a valuable tool for calculus learning & 2.44 & 1.209 & 4.53 & 1.100 \\
\hline Using GeoGebraas a tool cannot encourage creative learning environment of calculus & 3.11 & .545 & 4.13 & 1.174 \\
\hline Weighted mean & 2.76 & & 4.45 & \\
\hline
\end{tabular}

As shown in Table 7, the mean value of each variable in the pre-test was below the neutral scale. However, learners' response to one variable had almost a neutral mean value. The weighted mean was less than the neutral scale. In the pre-test, learners did not feel comfortable with the learning of calculus/mathematics. Overall, they disliked mathematics lessons. In contrast, the mean value of each variable in the post-test was greater than the neutral scale. The weighted mean was too. Thus, learners developed a very positive attitude in a way that they viewed the learning of calculus as easy, enjoyable and interesting. This was most likely due to the influence that incurred from learners' use of the JCLGS in their calculus learning.

The results shown in Table 8 revealed that learners' response to a few variables in the pre-test had a mean value less than the neutral scale. For most variables, the mean values are almost equal to the neutral scale. The weighted mean was approximately equal to the neutral scale. From this, it can be deduced that learners might have not been exposed to or familiarized with or they might have had a negative attitude to the learning of calculus integrated with computer software package/GeoGebra. However, in the post-test, the mean value of each variable and their weighted mean were higher than the neutral scale. So, learners have shown a 
Table 9. Frequency distribution to Overall Attitude

\begin{tabular}{cccccc}
\hline & \multicolumn{3}{c}{$\begin{array}{c}\text { Pre-test } \\
\text { Frequency (\%) }\end{array}$} & \multicolumn{3}{c}{$\begin{array}{c}\text { Post-test } \\
\text { Frequency (\%) }\end{array}$} \\
\hline A & N & D & A & N & D \\
\hline $321(15.93 \%)$ & $712(35.32 \%)$ & $983(48.76 \%)$ & $1640(81.35 \%)$ & $183(9.08 \%)$ & $193(9.57 \%)$ \\
\hline Note. A=Agreeing (Strongly Agree and Agree); N=Neutral; D=Disagreeing (Strongly disagree and disagree)
\end{tabular}

Note. A=Agreeing (Strongly Agree and Agree); N=Neutral; D=Disagreeing (Strongly disagree and disagree)

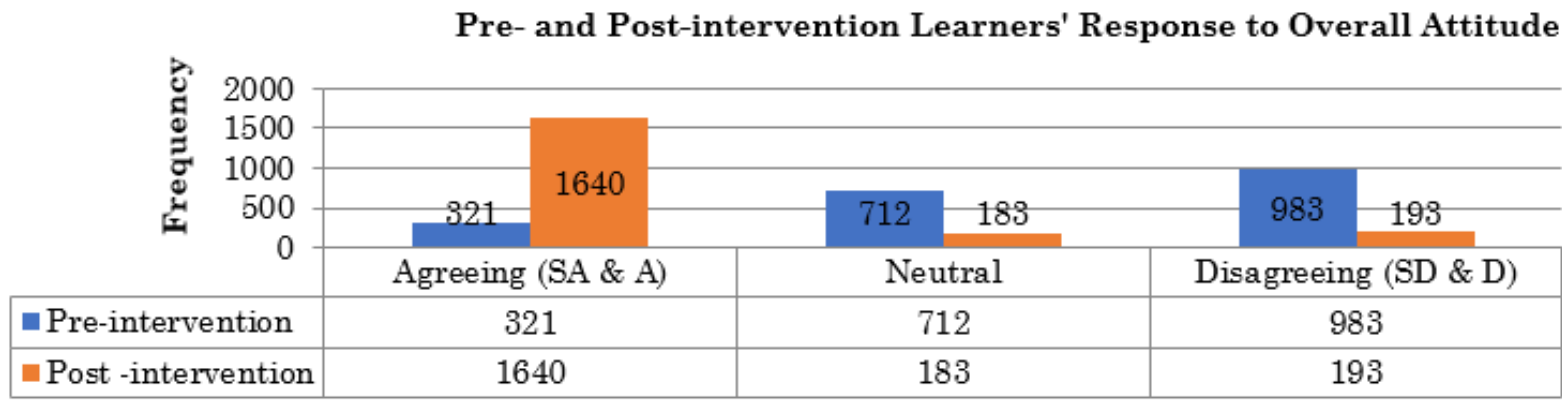

Figure 3. Bar graph to Learners Responses to Overall Attitudes

Table 10. Descriptive Statistics for Conceptual Knowledge Achievement Scores ( $n=150)$

\begin{tabular}{|c|c|c|c|c|}
\hline \multirow{2}{*}{ Statistics } & \multicolumn{2}{|c|}{ Pre-test } & \multicolumn{2}{|c|}{ Post-test } \\
\hline & CG & EG & CG & EG \\
\hline Valid & 75 & 75 & 75 & 75 \\
\hline Missing & 0 & 0 & 0 & 0 \\
\hline Mean & 13.800 & 13.906 & 15.206 & 29.480 \\
\hline Std. Error of Mean & .478 & .531 & .633 & 1.058 \\
\hline Median & 13.00 & 14.00 & 15.00 & 29.00 \\
\hline Variance & 17.162 & 21.221 & .490 & .760 \\
\hline Mode & 10.00 & $11.00^{\mathrm{a}}$ & $13.00^{\mathrm{a}}$ & 28.00 \\
\hline Std. Deviation & 4.142 & 4.606 & 5.482 & 9.162 \\
\hline Skewness & .642 & .109 & .587 & -.031 \\
\hline Kurtosis & .476 & -.586 & .026 & -.988 \\
\hline Range & 17.00 & 20 & 25.50 & 32.00 \\
\hline
\end{tabular}

Multiple modes exist. The smallest value is shown. EG=Experimental Group, $\mathrm{CG}=$ Control Group

positive attitudinal change in the pre-and post-test period to the learning of calculus with the blended learning JCLGS. The JCLGS substantially benefited learners in developing conceptual knowledge of calculus.

The frequency or percentage distribution for the overall learners' attitude is shown in Table 9. The percentage of participants responding by agreeing to post-test was $81.35 \%$. The percentage of participants responding by agreeing to the pre-test was $15.93 \%$.

Graphical representation of the frequency distribution is depicted in Figure 3.

As to the first research question/hypothesis, it is a good idea to make an initial judgment about the results shown in Table 10 in terms of measures of central tendency (mean) and dispersion. The mean (0.106) of the difference score in pre-test between experimental (EG) and comparison (CG) group was small. The mean (14.273) of the difference score in post-test between experimental (EG) and comparison (CG) group was very big. For the moment, the pre-test result justified that learners were almost in the same conceptual knowledge level before the intervention implemented. The post-test result can be taken as evidence that the JCLGS substantially improved learners' conceptual knowledge of calculus. It can be further verified using an independent-samples t-test and Two-Way ANOVA for repeated measures findings.

Next, the collected data are tested whether they meet the underlying assumptions in the independent samples t-test and Two-Way ANOVA for repeated measures or not (Field, 2009). Each sample unit was randomly drawn from the population of the experimental and comparison groups. The data measured by a ratio-scale of measurement as they represent learners' achievement scores. The score of each sample was independent of each other as it constitutes two different independent groups. 
Table 11. Kolmogorov-Smirnov Normality Test for Learners' Pre-test Achievement Scores

\begin{tabular}{lccccccc}
\hline & \multicolumn{4}{c}{ Kolmogorov-Smirnov $^{\mathrm{a}}$} & \multicolumn{3}{c}{ Shapiro-Wilk } \\
\hline Variable & Group & Statistic & df & Sig. & Statistic & df & Sig. \\
\hline Conceptual & EG & .083 & 75 & $.200^{*}$ & .986 & 75 & .553 \\
\cline { 2 - 10 } knowledge & CG & .137 & 75 & .001 & .943 & 75 & .002 \\
\hline
\end{tabular}

*. This is a lower bound of true significance. a. Lilliefors Significance Correction.

Table 12. Levene's Test for Equality of Variances for Learners' Pre-test Achievement Scores

\begin{tabular}{|c|c|c|c|c|c|}
\hline Variable & Groun & Levene Statistic & df1 & df? & Sig \\
\hline \multirow{2}{*}{ Conceptual knowledge } & $\mathrm{EG}$ & Based on Mean $\quad .88$ & 1 & 148 & .35 \\
\hline & $\mathrm{CG}$ & & & & \\
\hline
\end{tabular}

Table 13. Kolmogorov-Smirnov Normality Test for Learners' Post-test Achievement Scores

\begin{tabular}{lccccccc}
\hline & \multicolumn{4}{c}{ Kolmogorov-Smirnova } & \multicolumn{3}{c}{ Shapiro-Wilk } \\
\hline Variable & Group & Statistic & df & Sig. & Statistic & df & Sig. \\
\hline Conceptual & EG & .086 & 75 & $.200^{*}$ & .954 & .008 & 75 \\
knnowledge & CG & .058 & 75 & $.200^{*}$ & .988 & 75 \\
\hline
\end{tabular}

*. This is a lower bound of true significance. a. Lilliefors Significance Correction

Table 14. Levene's Test for Equality of Variances for Learners' Post-test Achievement Scores

\begin{tabular}{lcccccc}
\hline & \multicolumn{5}{c}{ Test of Homogeneity of Variance } \\
\hline Variable & Group & \multicolumn{2}{c}{ Levene Statistic } & df1 & df2 & Sig. \\
\hline \multirow{2}{*}{ Conceptual knowledge } & EG & Based on Mean & .353 & 1 & 148 & \\
\cline { 2 - 7 } & CG & & & & & \\
\end{tabular}

As shown in Table 11, normality for each pair of data set can be tested using the Kolmogorov-Smirnov normality test. As Pallant and Manual (2010) pointed out, the Kolmogorov-Smirnov test value that quantifies the normality of the distribution of scores can be determined using the significance value (Sig.). The significance value less than 0.05 (significant) indicate non-normality of distribution while significance value more than 0.05 (non-significant) shows normality. According to Field (2009); Green and Salkind (2005), the Kolmogorov-Smirnov test statistic denoted as D reported with the degree of freedom (df) and significance level (sig.). Thus, the Kolmogorov-Smirnov test result for the pre-test conceptual knowledge achievement score of the experimental and comparison groups was, respectively, $D(75)=.200, p>0.05$ and $D(75)=.001, p<0.05$. The data on learners' conceptual knowledge achievement scores of the experimental group was normally distributed while the comparison group was non-normal. However, by the Central Limit Theorem, data on learners' conceptual knowledge achievement scores of comparison group tend to normality as the sample size was large (Field, 2009; Green \& Salkind, 2005; Pallant \& Manual, 2010).

As depicted in Table 12, homogeneity of variances for each pair of data set has been tested using Levene's test. Based on these results, the equality of the variances of the populations from which the sample groups drawn can be detected. According to Green and Salkind (2005), Levene's test denoted as F described with a degree of freedom and reported as $\mathrm{F}\left(\mathrm{df}_{1}, \mathrm{df}_{2}\right)=v a l u e$, sig. So, the Levene's test for data on learners' pre-test conceptual knowledge achievement scores of experimental and comparison groups was observed to be $F(1$, 148)=.88, ns. The distribution of scores implies that the variances of the dependent variable for the two populations were equal.

The homogeneity of variances for post-test data can be analyzed as quite similar to the pre-test. Square root transformation has been done on post-test data. As shown in Table 13, the Kolmogorov-Smirnov statistics for post-test data of the experimental and comparison groups were respectively observed as $D(75)=.200, p>0.05$ and $D(75)=.200, p>0.05$. The distribution of scores for the experimental and comparison groups was normal.

As shown in Table 14, the Levene's test statistic for data on post-test conceptual knowledge achievement scores of both groups was observed to be $F(1,148)=.353$, $n s$. This implies that the variances for the dependent variable of both populations were equal.

The independent-samples t-test results and effect size measure on pre-test in line with the null hypothesis $\left(\mathrm{H}_{0}\right)$ is depicted in Table 15. According to Cohen et al. (2007); Field (2009); Green and Salkind, (2005), eta squared is a suitable statistical tool to measure the effect size value for the independent samples t-test. The effect size value eta squared=.00014 represents a very small-sized effect. As Green and Salkind suggest, this index indicates that there was no statistically significant difference between experimental $(M=13.907$, 
Table 15. Independent Samples t-test Results and Effect size Value for Pre-test

\begin{tabular}{|c|c|c|c|c|c|c|c|c|c|}
\hline \multirow{3}{*}{ Variable } & \multicolumn{3}{|c|}{$\begin{array}{c}\text { Levene's Test for } \\
\text { Equality of Variances }\end{array}$} & \multicolumn{5}{|c|}{ t-test for Equality of Means } & \multirow{3}{*}{$\begin{array}{c}\text { Eta } \\
\text { Squared }\end{array}$} \\
\hline & \multirow{2}{*}{$\mathbf{F}$} & \multirow{2}{*}{ Sig. } & \multirow{2}{*}{$\mathbf{t}$} & \multirow{2}{*}{ df } & \multirow{2}{*}{$\begin{array}{l}\text { Sig. (2- } \\
\text { tailed) }\end{array}$} & \multirow{2}{*}{$\begin{array}{c}\text { SE of } \\
\text { difference }\end{array}$} & \multicolumn{2}{|c|}{$95 \%$ CI } & \\
\hline & & & & & & & $\mathbf{L L}$ & UL & \\
\hline $\begin{array}{l}\text { Conceptual } \\
\text { knowledge }\end{array}$ & .87 & .35 & .149 & 148 & .88 & .71 & -1.30 & 1.52 & 0.00014 \\
\hline
\end{tabular}

${ }^{*} \mathrm{p}<0.05, \mathrm{CI}=$ Confidence Interval, LL=Lower Limit, UL=Upper Limit

Table 16. Independent Samples t-test Results and Effect size Value for Post-test

\begin{tabular}{|c|c|c|c|c|c|c|c|c|c|}
\hline \multirow{3}{*}{ Variable } & \multicolumn{3}{|c|}{$\begin{array}{c}\text { Levene's Test for } \\
\text { Equality of Variances }\end{array}$} & \multicolumn{6}{|c|}{ t-test for Equality of Means } \\
\hline & & & & & Sig. (2- & SE of & & & \\
\hline & $\mathbf{F}$ & Sig. & $\mathrm{t}$ & df & tailed) & difference & $\mathbf{L L}$ & UL & Squared \\
\hline $\begin{array}{l}\text { Conceptual } \\
\text { knowledge }\end{array}$ & 22.87 & .000 & 11.576 & 148 & .000 & 1.23 & 11.83 & 16.70 & 0.48 \\
\hline
\end{tabular}

${ }^{*} \mathrm{p}<0.05, \mathrm{CI}=$ Confidence Interval, LL=Lower Limit, UL=Upper Limit

Table 17. Descriptive Statistics for Pre-test and Post-test Conceptual Knowledge Achievement Scores

\begin{tabular}{cccccc}
\hline & & \multicolumn{2}{c}{ Pre-test } & \multicolumn{2}{c}{ Post-test } \\
\hline Group & n & M & SD & M & SD \\
\hline EG & 75 & 13.906 & 4.406 & 29.480 & 9.162 \\
\hline CG & 75 & 13.800 & 4.142 & 15.206 & 5.482 \\
\hline
\end{tabular}

$S E=.531)$ and comparison groups $(M=13.800, S E=.478) ; t(148)=.149, p>0.05,95 \%$ CI [-1.30, 1.52]. This implies that the data were in favour of the null hypothesis. Hence, this result can be interpreted as in the pre-test both experimental and comparison group learners had almost the same conceptual knowledge level.

Table 16 depicts the independent samples t-test results and effect size measure for post-test. The effect size value was a very big one (Green \& Salkind, 2005). As a result, there was a statistically significant difference between experimental $(M=29.480, S E=1.058)$ and comparison groups $(M=15.207, S E=.633)$; $t(148)=11.576, p<0.05,95 \%$ CI $[11.836,16.709]$. The data were in favour of the alternative hypothesis. Therefore, this result can be interpreted as learners in the experimental group nurtured with the JCLGS substantially benefited in developing their conceptual knowledge of calculus.

The null hypothesis also analyzed using Two-Way ANOVA for repeated measures and then the corresponding results interpreted as the underlying assumptions met by the collected data for both experimental and comparison groups. The purpose of using Two-Way ANOVA for repeated measures was to determine whether the pre-test to post-test mean scores increment between the experimental and comparison group was statistically significantly different or not. In other words, it aimed to identify whether the influence of the intervention/JCLGS on experimental group learners' knowledge development of calculus is meaningful or not.

Before Two-Way ANOVA for repeated measures analysis carried on $\mathrm{H}_{01}$, it was thought vital to present the descriptive statistics of pre-test and post-test conceptual knowledge achievement scores in both experimental and comparison groups. This will help us to make an initial inspection based on the pattern of these statistics to judge the influence of the independent variable(s) (Pallant, 2010).

Also, the line graph shown in Figure 4 could assist us to inspect how much the mean incremental difference was statistically significant between learners in the experimental and comparison groups from pretest to post-test on conceptual knowledge achievement scores of calculus. 


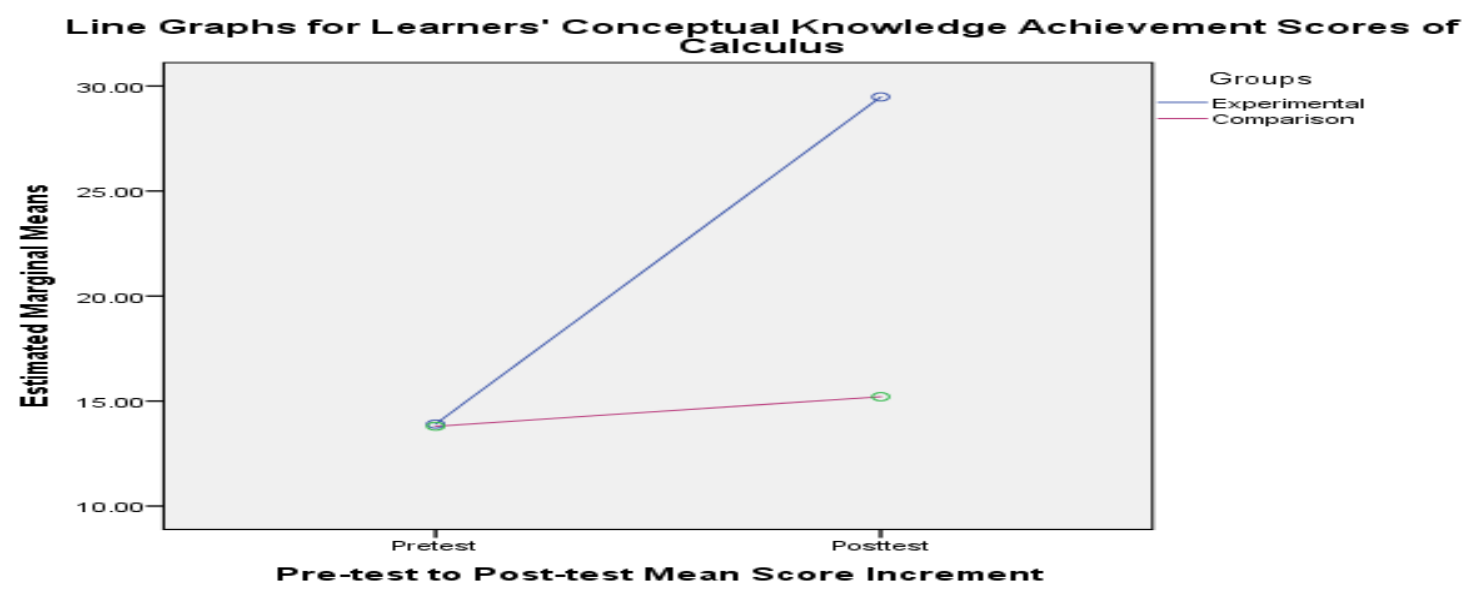

Figure 4. Conceptual Knowledge Development of Calculus for Experimental and Comparison Groups

Table 18. ANOVA Results for Pre-test and Post-test Conceptual Knowledge Achievement Scores of the Experimental and Comparison groups

\begin{tabular}{|c|c|c|c|c|c|c|}
\hline Source of Variance & Sum of Squares & df & Mean Score & $\mathbf{F}$ & $\eta^{2}$ & $\mathbf{p}$ \\
\hline \multicolumn{7}{|c|}{ Between Groups } \\
\hline Group & 5406.008 & 1 & 5406.008 & 131.84 & .471 & $.000^{*}$ \\
\hline Error & 6068.467 & 148 & 41.003 & & & \\
\hline \multicolumn{7}{|c|}{ Within Groups } \\
\hline Pre-Post Test Measures & 3877.208 & 1 & 3877.208 & 110.158 & .427 & $.000^{*}$ \\
\hline Pre-Post test*Group & 3763.021 & 1 & 3763.021 & 106.913 & .419 & $.000^{*}$ \\
\hline Error & 5209.147 & 148 & 35.197 & & & \\
\hline
\end{tabular}

$* \mathrm{p}<.01$

It can be seen from Figure 4 that the mean for conceptual knowledge achievement score of learners' in the experimental group increased from the pre-test $(M=13.906)$ to the post-test $(M=29.480)$ with increment 15.574. The mean score increment from pre-test $(M=13.800)$ to post-test $(M=15.206)$ for comparison group learners' was 1.406. The increment for the experimental group was substantial compared to the comparison group after the intervention. Whether this big incremental difference was statistically significant or not could be further justified using the Two-Way ANOVA for repeated measures analysis procedures. The results of Two-Way ANOVA for repeated measures analysis are shown in Table 18.

The analysis results in Table 18 shows that there was a statistically significant mean incremental difference between experimental and comparison groups after the intervention. The effect of pre-test and posttest conducted on learners of both experimental and comparison groups in their conceptual knowledge development of calculus was statistically significant $\left[F(1,148)=106.913 ; \eta^{2}=.419 ; p<.01\right]$. According to Cohen et al. (2007); Pallant (2007), the effect size value represents a very large effect. Consequently, learners in the experimental group substantially benefited in developing conceptual knowledge of calculus after having exposed to the JCLGS grounded in social constructivism cognitive development learning theory. This is as compared to the comparison group that was taught calculus by using the traditional lecture method.

\section{DISCUSSION}

Learners exposed to the JCLGS have developed a great deal of conceptual knowledge and positive attitudinal change towards calculus and GeoGebra. Though the traditional lecture method influenced the comparison group learners in enhancing their conceptual knowledge development during pre- and post-test as well, this is not incomparable to that of the JCLGS. The effect size value eta squared=.419 could be taken as a valuable indicator. The attention and care are given to the intervention over a semester could too. Given learners' achievement towards conceptual knowledge, the finding of this study with $t(148)=11.576$ and effect size value eta squared=.48, was by far different from that of similar or other related reviewed literature, for instance, (Ocal, 2017) with $\mathrm{t}(53)=2.786$. The same reason holds that the finding of this study was also by far different from Oktaviyanthi and Supriani (2015); Zulnaidi and Zamri (2017); Zulnaidi and Zakaria (2012) on learners' conceptual knowledge achievement score. The reason for this was the JCLGS has substantially 
influenced learners learning of calculus. The intervention was a kind of learning strategy integrates learning activities prepared by the researcher, the active jigsaw co-operative learning method and the software package GeoGebra as a tool. These things influenced learners to be most conceptual than those participants involved in other related or similar studies. This can be justified by the observed effect size value eta squared=.48 measured the influence of the JCLGS on learners' conceptual knowledge development. This value was a very large one as compared to those values reported in other related or similar studies. You can imagine based on this value how much the effect of the JCLGS on learners learning of conceptual knowledge was.

\section{CONCLUSION}

The experimental group learners effectively used the active JCLGS in their calculus learning. The obtained findings are evidence of that. The JCLGS statistically and practically influenced learners' conceptual knowledge development of calculus. The effect size value on conceptual knowledge of the present study is by far too big from other related studies. The use of the JCLGS substantially enhanced learners' conceptual and content knowledge development of various lessons of calculus. It allowed them to visualize those abstract calculus objects that may not be possible by traditional lecture method which are mostly carried out using a black/whiteboard. These are through numerically, symbolically, geometrically, algebraically/formula and calculus means representations of various calculus contents. One of the important reasons for this is GeoGebra has interactive environments capable of representing abstract concepts in a variety of ways. The JCLGS also influenced learners' in changing their attitude positively towards calculus and GeoGebra. Learners experienced reflection and communication skills and general social learning through it. Learners' success in conceptual knowledge learning contributed a lot to their content knowledge development. Learners' exposure to such kind of learning strategy informed them to be conscious to know all about other active learning methods and mathematics software packages used for teaching/learning. Azmin (2016) reported that the jigsaw co-operative learning method applied on learners' learning of psychology significantly benefited them to perform, achieve and to have a positive opinion towards the method as compared to the traditional lecture method. However, this study used this method without integrating it with technology. The findings $t(148)=11.576$ and effect size value (1.920) of the present study is more than twice as big as the findings $t(28)=4.730$ and effect size value (0.666) of the study conducted by Azmin. This is one instance that makes this present study differs from the previous study. In conclusion, no research literature has ever been reported on the significance of the learning strategy that integrates the active jigsaw co-operative learning strategy and GeoGebra as a tool in learners' learning of calculus.

\section{RECOMMENDATIONS}

The researcher cannot dare to say that the findings as exhaustive ones. However, the researcher tried his best for this calculus learning challenge to be reduced by preparing learning activities and creating a conducive learning environment. Experimental group learners allowed to effectively using the active JCLGS. In the course of this, the researcher and the data collectors have made their maximum effort to avoid any sort of flaws. The researcher is not meant that the study is conducted without limitations. You all know that most often educators/scholars remind instructors about active learning methods all over the world to implement in classroom instruction. Be aware that, it is currently being introduced in the Ethiopian higher institutions. The researcher would like to recommend stakeholders such as mathematics and science curriculum developers, policymakers, teachers training colleges and university instructors, mathematics and science school teachers, prospective teachers from mathematics and science graduates in the Ethiopia context and scientific research community could take the findings of this study as input for their career. For instance, school teachers, college instructors and university instructors of mathematics and science could apply the theories and findings inculcated in this study while presenting their lessons. This can be done first prepare learning activities in each daily lesson, select appropriate active learning method and try integrating this method with appropriate software package if there is and then apply to form a group consisting of 4 or 5 learners. This is because it would enable learners to better perform and achieve conceptual knowledge of calculus. It would also enable them to have a positive attitude towards the calculus lessons they learn and to the active learning method integrated with technology. Teachers training colleges could also mainstream and use this learning model in training teachers in their professional development. The scientific research community could also view the finding of this study as input to add a contribution to the solution of this same problem. 


\section{LIMITATIONS}

The very nature of the non-equivalent pre-and post-test comparison group quasi-experimental design was one of the limitations to this study. The violence took place around the two research universities, delay and absentees of very few research participants during the intervention were the other limitations to the study. A few of the research participants were also unable to become proficient in GeoGebra in the stipulated training time. The small number of research areas selected from the second generation Ethiopian universities was also the other constraint. However, with all these constraints this study came up with remarkable findings that are of big practical significance in other mathematical learning situations.

\section{Disclosure statement}

No potential conflict of interest was reported by the authors.

\section{Notes on contributors}

Sirak Tsegaye Yimer - Ambo University, College of Natural and Computational Sciences, Mathematics Department, Ambo, Oromia, Ethiopia.

Nosisi Nellie Feza - Central University of Technology, Faculty of Humanities, Free State (CUT) Private Bag X20539, Bloemfontein, 9300, South Africa.

\section{REFERENCES}

Adebule, S. O. (2009). Reliability and levels of difficulty of objective test items in a Mathematics achievement test: A study of ten senior secondary schools in five local government areas of Akure, Ondo State. Educational Research and Reviews, 4(11), 585-587.

Alkhateeb, M. A., \& Al-Duwairi, A. M. (2019). The Effect of Using Mobile Applications (GeoGebra and Sketchpad) on the Students' Achievement. International Electronic Journal of Mathematics Education, 14(3), 523-533. https://doi.org/10.29333/iejme/5754

Amineh, R. J., \& Asl, H. D. (2015). Review of constructivism and social constructivism. Journal of Social Sciences, Literature and Languages, 1(1), 9-16.

Arbin, N., Ghani, S. A., \& Hamzah, F. M. (2014, June). Teaching calculus using module based on cooperative learning strategy. AIP Conference Proceedings, 1602(1), 497-501. https://doi.org/10.1063/1.4882531

Arbini, C. (2016). The Impact of Graphing Calculators on Math Achievement: A Quantitative, Longevity Analysis. ProQuest LLC. 789 East Eisenhower Parkway, PO Box 1346, Ann Arbor, MI 48106.

Awang, N., \& Hamid, N. N. A. (2015, October). Students attitude towards calculus subject: A case-study using structural equation modeling. AIP Conference Proceedings, 1682(1), 050012.1-050012.5). https://doi.org/10.1063/1.4932503

Awang, N., Ilias, M. R., Che Hussain, W. S. E., \& Mokhtar, S. F. (2013, April). Students attitude towards calculus subject: Bumiputera case-study. In AIP Conference Proceedings, 1522(1), 392-395. https://doi.org/10.1063/1.4801151

Ayub, A. F. M., Sembok, T. M., \& Luan, W. S. (2008). Teaching and learning calculus using computer. Semantics scholar, 1-10. Retrieved from http://atcm.mathandtech.org/ep2008/papers_full/2412008_ 15028.pdf

Azmin, N. H. (2016). Effect of the Jigsaw-Based Cooperative Learning Method on Student Performance in the General Certificate of Education Advanced-Level Psychology: An Exploratory Brunei Case Study. International Education Studies, 9(1), 91-106. https://oi.org/10.5539/ies.v9nlp91

Ball, D. L., Thames, M. H., \& Phelps G. (2008). Content knowledge for teaching: What makes it special?. Journal of Teacher Education, 59(5), 389-407. Retrieved from http://jte.sagepub.com

Bezuidenhout, J. (2001). Limits and continuity: Some conceptions of first-year students. International Journal of Mathematical Education in Science and Technology, 32(4), 487-500. https://oi.org/10.1080/ 00207390010022590

Boopathiraj, C., \& Chellamani, K. (2013). Analysis of test items on difficulty level and discrimination index in the test for research in education. International Journal of Social Science \& Interdisciplinary Research, $2(2), 189-193$. 
Boz Yaman, B. (2019). A Multiple Case Study: What Happens in Peer Tutoring of Calculus Studies?. International Journal of Education in Mathematics, Science and Technology, 7(1), 53-72. https://doi.org/10.18404/ijemst/328336

Bransford, Brown, C. (1999). How People Learn: Brain, Mind, Experience and School. Washington, D.C.: National Academy Press.

Brown, J. D. (2001). Point-biserial correlation coefficients. Shiken: JLT Testing and Evaluation SIG Newsletter, 5(3), 13-17. Retrieved from http://jlt.org/test/bro_12.htm or http://jlt.org/test/PDF/Brown12.pdf

Castellan, C. M. (2010). Quantitative and qualitative research: A view for clarity. International journal of education, 2(2), 1-14. https://doi.org/10.5296/ije.v2i2.446

Chinnappan, M., \& Forrester, T. (2014). Generating procedural and conceptual knowledge of fractions by preservice teachers. Mathematics Education Research Journal, 26(4), 871-896. https://doi.org/10.1007/s13394-014-0131-x

Cobb, P., \& Bauersfeld, H. (Eds.). (1995). The emergence of mathematical meaning: Interaction in classroom cultures. Psychology Press.

Cohen, L., Manion, L., \& Morrison, K. (2007). Approaches to qualitative data analysis. Research methods in education. https://doi.org/10.4324/9780203029053

Cornelius, M., \& Ernest, P. (1991). The Philosophy of Mathematics Education. Springer Nature. https://doi.org/10.1007/978-3-319-40569-8

Costa, P., Oliveira, P. \& Ferrão, M. E. (2009). Statistical issues on multiple choice tests in engineering assessment. In Proceedings of the 37th Sefi Conference, Rotterdam, Delft University of Technology, 1-7.

Creswell, J. W., \& Creswell, J. D. (2017). Research design: Qualitative, quantitative, and mixed methods approaches. Sage publications.

Demircioglu, G., Aslan, A., \& Yadigaroglu, M. (2014). Exploratory Factor Analysis Study for the Scale of High School Students' Attitudes towards Chemistry. International Journal on New Trends in Education and their Implications, 5(1), 38-45.

Ding, L., \& Beichner, R. (2009). Approaches to data analysis of multiple-choice questions. Physical Review Special Topics - Physics Education Research, 5(2), 0201039(1-17). https://doi.org/10.1103/PhysRevSTPER.5.020103

Engelbrecht, J., Bergsten, C., \& Kågesten, O. (2012). Conceptual and procedural approaches to mathematics in the engineering curriculum: Student conceptions and performance. Journal of Engineering Education, 101(1), 138-162. https://doi.org/10.1002/j.2168-9830.2012.tb00045.x

Engelbrecht, J., Harding, A., \& Potgieter, M. (2005). Undergraduate students' performance and confidence in procedural and conceptual mathematics. International Journal of Mathematical Education in Science and Technology, 36(7), 701-712. https://doi.org/10.1080/00207390500271107

Field, A. (2009). Discovering Statistics Using SPSS, Third Edition. Sage publications.

Fraenkel, J. R, Norman E., \& Wallen. (2009). How to design and evaluate research in education. New York: McGrow-Hill.

Fraser, B. J. (1981). Tosra: Test of science related attitudes: Handbook. Australian Council for Educational Research.

Gelo, O. C. G. (2012). On research methods and their philosophical assumptions: "raising the consciousness of researchers" again. Psychotherapie und Sozialwissenschaft, 14(2), 111-130.

Getie, B. (2013). Mathematics Subject Area Method I for Secondary. Post Graduate Diploma in Teaching, 2(1), 3-6.

Graham, M., Milanowski, A., \& Miller, J. (2012). Measuring and Promoting Inter-Rater Agreement of Teacher and Principal Performance Ratings. Online Submission, ED532066, 1-33.

Gray, A. J. (1997). Constructivist teaching and learning. Saskatchewan School Trustees Association.

Gray, D. E. (2013). Doing research in the real world. Sage Publications.

Green, S. B., \& Salkind, N, J. (2005). Using SPSS for Windows and Macintosh: Internal consistency estimates of reliability. Upper Saddle River, NJ: Pearson Prentice Hall.

Heibert, J., \& Lefevre, P. (1986). Conceptual and procedural knowledge: The case of mathematics. Hillsdale, NJ, Erlbaum. https://doi.org/10.4324/9780203063538 
Highfield, K, \& Goodwin, K. (2008). A review of recent research in early mathematics learning technology. In Navigating charts and charting directions: Proceedings of the 31st Annual Conference of MERG.Brisbane: Mathematics Education Research Group of Australasia.

Hoover, W. A. (1996, August). The practice implications of constructivism. SEDL Letter, 9(3). Retrieved from www.sedl.org/pubs/sedletter/v09n03/practice.html

Huang, C. H. (2011). Investigating the attitudes toward calculus of engineering students in Taiwan. World Transactions on Engineering and Technology Education, 9(2), 80-85.

Jaafar, R., \& Lin, Y. (2017). Assessment for Learning in the Calculus Classroom: A Proactive Approach to Engage Students in Active Learning. International Electronic Journal of Mathematics Education, 12(3), 503-520.

Johnson, B., \& Christensen, L. (2014). Educational research: Quantitative, Qualitative and Mixed approaches. Sage Publications.

Kadijević, Đ. (1999). Conceptual tasks in mathematics education. The Teaching of Mathematics, 2(1), 59-64. Retrieved from https://eudml.org/doc/255835

Kandemir, M. A., \& Demirbag-Keskin, P. (2019). Effect of Graphing Calculator Program Supported Problem Solving Instruction on Mathematical Achievement and Attitude. International Journal of Research in Education and Science, 5(1), 203-223. Retrieved from https://files.eric.ed.gov/fulltext/EJ1197997.pdf

Khashan, K. H. (2014). Conceptual and procedural knowledge of rational numbers for Riyadh elementary school teachers. Journal of Education and Human development, 3(4), 181-197. https://doi.org/10.15640/jehd.v3n4a17

Khine, M. S. (Ed.). (2013). Application of structural equation modeling in educational research and practice (Vol. 7). Rotterdam, NL: Sense Publishers. https://doi.org/10.1186/s40064-015-1650-y

Kilicman, A., Hassan, M. A., \& Husain, S. K. (2010). Teaching and learning using mathematics software "The New Challenge". Procedia-Social and Behavioral Sciences, 8, 613-619. https://doi.org/10.1016/j.2010.12.085

Kiliyanni, A. L., \& Sivaraman, S. (2016). The perception-reality gap in financial literacy: Evidence from the most literate state in India. International Review of Economics Education, 23, 47-64. https://doi.org/10.1016/j.iree.2016.07.001

Kim, B. (2001). Social constructivism. Emerging perspectives on learning, teaching, and technology, 1(1), 16. ed. M. Orey. Retrieved from https://projects.coe.uga.edu/epltt/index.php

Kline, P. (1986). A handbook of test construction: Introduction to psychometric design. New York, NY: Methuen.

Koehler, M., \& Mishra, P. (2009). What is technological pedagogical content knowledge (TPACK)?. Contemporary issues in technology and teacher education, 9(1), 60-70.

Kridler, P. G. (2012). Procedural and Conceptual Knowledge: A Balanced Approach? (Doctoral dissertation). Available from ProQuest Dissertations and Theses database (UMI No. 3521915)

Kuder, G. F., \& Richardson, M. W. (1937). The theory of the estimation of test reliability. Psychometrika, 2(3), 151-160. https://doi.org/10.1007/BF02288391

Kukla, A. (2013). Social constructivism and the philosophy of science. Routledge. https://doi.org/10.4324/9780203130995

Lavicza, Z. (2010). Integrating technology into mathematics teaching at the university level. $Z d m, 42(1), 105$ 119. https://doi.org/10.1007/s11858-009-0225-1

Lee, A. (2012). The effects of computer-based learning activities and school contextual factors on student math achievement. Leadership and Policy Quarterly, 1(1), 58-72. Retrieved from https://www. untestedideas. com/uploads/3/1/1/6/3116134/factors_affecting_student_math_achievement.pdf

Liao, S. C., Hunt, E. A., \& Chen, W. (2010). Comparison between inter-rater reliability and inter-rater agreement in performance assessment. Annals Academy of Medicine Singapore, 39(8), 613-618.

Lim-Teo, S. K., Ahuja, O. P., \& Lee, P. Y. (1999). Tertiary and junior college students' attitude towards mathematics. The Mathematics Educator, 4(1), 15-33.

Maltas, D., \& Prescott, A. (2014). Calculus-based mathematics: An Australian endangered species?. Australian Senior Mathematics Journal, 28(2), 39-49.

Mazana, Y. M., Suero Montero, C., \& Olifage, C. R. (2019). Investigating Students' Attitude towards Learning Mathematics. International Electronic Journal of Mathematcs Edcation, 14(1), 207-231. https://doi.org/10.29333/iejme/3997 
McMahon, M. (1997). Social constructivism and the World Wide Web-A paradigm for learning', paper presented to ASCILITE conference, (327), 411-417. Perth, Australia. Retrieved from Retrieved from http://www.ascilite.org.au/conferences/perth97/Mcmahon/Mcmahon.html

Nenty, H. J. (2009). Writing a quantitative research thesis. International Journal of Educational Sciences, $1(1), 19-32$.

Ocal, M. F. (2017). The Effect of GeoGebra on Students' Conceptual and Procedural Knowledge: The Case of Applications of Derivative. Higher Education Studies, 7(2), 67-78. https://doi.org/10.5539/hes.v7n2p67

Oktaviyanthi, R., \& Supriani, Y. (2015). Experimental Design: Utilizing Microsoft Mathematics in Teaching and Learning Calculus. Journal of Education and Practice, $6(25), \quad 75 \quad-83$. https://doi.org/10.22342/jme.6.1.1902.63-76

Orey, M. (2010). Emerging perspectives on learning, teaching and technology. North Charleston: CreateSpace.

Othman, Z. S., Tarmuji, N. H., \& Hilmi, Z. A. G. (2017, April). Students perception on the usage of PowerPoint in learning calculus. In AIP Conference Proceedings, 1830(1), 050005(1-7). AIP Publishing. https://doi.org/10.1063/1.4980942

Pallant, J., \& Manual, S. S. (2010). A step by step guide to data analysis using SPSS. Berkshine, UK: McGrawHill Education.

Parrot, M. A. S., \& Leong, K. E. (2018) Impact of using graphing calculator in problem solving. International Electronic Journal of Mathematics Education, 13(3), 139-148. https://doi.org/10.12973/iejme/2704

Peteros, E., Columna, D., Etcuban, J. O., Almerino, Jr., P., \& Almerino, J. G. (2019). Attitude and Academic Achievement of High School Students in Mathematics Under the Conditional Cash Transfer Program. International Electronic Journal of Mathematics Education, 14(3), 583-597. https://doi.org/10.29333/iejme/5770

Pilgrim, M. E. (2010). A concepts for calculus intervention: Measuring student attitudes toward mathematics and achievement in calculus (Doctoral dissertation, Colorado State University. Libraries). Retrieved from Dissertations \& Theses @ Colorado State University.(Publication No. AAT3419112).

Roth, W. M. (1999). Authentic school science: Intellectual traditions. Learning and knowledge. London: Paul Chapman Publishing.

Saunders, M. N. K., Lewis, P., \& Thornhill, A. (2009). Research methods for business students (5 ${ }^{\text {th }}$ Ed.). Pearson education Limited, Harlow.

Siyepu, S. (2013). The zone of proximal development in the learning of mathematics. South African Journal of Education, 33(2), 1-13. Retrieved from http://www.sajournalofeducation.co.za

Sofroniou, A., \& Poutos, K. (2016). Investigating the effectiveness of group work in mathematics. Education Sciences, 6(30), 1-15. https://doi.org/10.3390/educsci6030030

Star, J. R., \& Stylianides, G. J. (2013). Procedural and conceptual knowledge: exploring the gap between knowledge type and knowledge quality. Canadian Journal of Science, Mathematics and Technology Education, 13(2), 169 -181. https://doi.org/10.1080/14926156.2013.784828

Summit, R., \& Rickards, T. (2013). A constructivist approach to mathematics laboratory classes. In Proceedings of the 9th DELTA Conference on Teaching and Learning of Undergraduate Mathematics and Statisitcs (pp. 190-198).

Vygotsky, L. S. (1980). Mind in society: The development of higher psychological processes. Harvard university press. https://doi.org/10.2307/j.ctvjf9vz4

Wertsch, J. V. (1985). Vygotsky and the social formation of mind. Harvard University Press.

Yilmaz, K. (2013). Comparison of quantitative and qualitative research traditions: Epistemological, theoretical, and methodological differences. European Journal of Education, 48(2), 311-325. Retrieved from https://www.jstor.org/stable/26357806

Yimer, S. (2016). Use of Computer Interactive Simulation on Conceptual and Procedural Knowledge of Calculus (Doctoral proposal), UNISA, 1-4.

Yong, A. G., \& Pearce, S. (2013). A beginner's guide to factor analysis: Focusing on exploratory factor analysis. Tutorials in quantitative methods for psychology, 9(2), 79-94. https://doi.org/10.20982/tqmp.09.2.p079

Young, C. Y., Georgiopoulos, M., Hagen, S. C., Geiger, C. L., Dagley-Falls, M. A., Islas, A. L., ... \& Bradbury, E. E. (2011). Improving student learning in calculus through applications. International Journal of Mathematical Education in Science and Technology, 42(5), 591-604. https://doi.org/10.1080/0020739X.2010.550944 
Zulnaidi, H., \& Zakaria, E. (2012). The Effect of Using GeoGebra on Conceptual and Procedural Knowledge of High School Mathematics Students. The Journal Asian Social Science, 8(11), 102-106. https://doi.org/10.5539/ass.v8n11p102

Zulnaidi, H., \& Zamri, S. N. A. S. (2017). The effectiveness of the GeoGebra software: the intermediary role of procedural knowledge on students' conceptual knowledge and their achievement in mathematics. Eurasia Journal of Mathematics, Science and Technology Education, 13(6), 2155-2180. https://doi.org/10.12973/eurasia.2017.01219a 